\title{
Release of Volatile Per- and Polyfluoroalkyl Substance from Aqueous Film-Forming Foam
}

3 Julia Roth, ${ }^{¥}{ }^{¥}$ Ibrahim Abusallout, ${ }^{2} ¥$ Tiffany Hill, ${ }^{3}$ Chase Holton, ${ }^{4}$ Utsav Thapa, ${ }^{2}$ and David

${ }^{1}$ Clean Vapor LLC, Charlotte, NC, USA.

$6 \quad 2$ Department of Civil and Environmental Engineering, University of Nevada, Reno, NV 89557-

7 0258, USA.

$8{ }^{3}$ Jacobs Engineering Group Inc., Dallas, Texas, USA.

$9{ }^{4}$ Geosyntec Consultants Inc., Denver, CO, USA.

$10{ }^{¥}$ Both authors contributed equally to this manuscript

$12 *$ Corresponding Author

13 Email: dhanigan@unr.edu

14 Phone: 775-682-7517

17 No. of pages: 57

18 No. of figures: 38

19 No. of tables: 12 


\begin{tabular}{|c|c|c|}
\hline Table/Figure & Title & Page \# \\
\hline Table S1 & PFASs analytes and CAS number for TD-GC-MS analysis. & 4 \\
\hline Table S2 & PFASs analytes and CAS number for XAD/PUF LC-MS/MS analysis. & 5 \\
\hline Table S3 & $\begin{array}{l}\text { Typical physiochemical characteristics of C306-MS-C 3\% AFFF concentrate at } \\
\qquad 25^{\circ} \mathrm{C} \text {, provided by manufacturer's datasheet. }\end{array}$ & 6 \\
\hline Table S4 & $\begin{array}{c}\text { Chemical composition of C306-MS-C 3\% AFFF concentrate provided by } \\
\text { manufacturer’s datasheet. }\end{array}$ & 6 \\
\hline Table S5 & $\begin{array}{l}\text { Experiments conducted above agitated AFFF to capture potential gas-phase } \\
\text { PFASs }\end{array}$ & 7 \\
\hline Table S6 & Relative humidity and temperature during experimental operation & 7 \\
\hline Table S7 & $\begin{array}{l}\text { PFASs concentrations sampled by TD samplers immediately and } 1 \mathrm{~h} \text { after } \\
\text { AFFF agitation }\end{array}$ & 15 \\
\hline Table S8 & $\begin{array}{l}\text { PFASs concentrations sampled by XAD/PUF samplers after continuously } \\
\text { sampling the AFFF headspace gas for } 1 \text { and } 24 \mathrm{~h}\end{array}$ & 17 \\
\hline Table S9 & Estimated vapor concentrations for selected PFASs & 18 \\
\hline Table S10 & $\begin{array}{l}\text { Tentatively identified hydrocarbons from TD sampler after sampling AFFF } \\
\text { headspace for } 2 \mathrm{~min}\end{array}$ & 19 \\
\hline Table S11 & $\begin{array}{l}\text { List of putatively identified and confirmed PFAS from the TD sampler after } \\
\text { sampling AFFF headspace for } 2 \mathrm{~min}\end{array}$ & 21 \\
\hline Table S12 & Proposed identification confidence criteria for the non-target compounds & 22 \\
\hline Figure S1 & Schematic illustrating the AFFF chambers experimental setup & 7 \\
\hline Figure S2 & XAD/Polyurethane foam air sampler diagram & 9 \\
\hline Figure S3 & Mass spectrum and retention time for PFOA standard injected into GC-MS & 16 \\
\hline Figure S4 & $\begin{array}{c}\text { GC-MS total ion chromatogram of TD sampler after sampling AFFF headspace } \\
\text { for } 24 \text { hours }\end{array}$ & 20 \\
\hline Figure S5 & $\begin{array}{c}\text { GC-MS total ion chromatogram of TD sampler after sampling AFFF headspace } \\
\text { for } 2 \text { min }\end{array}$ & 20 \\
\hline Figure S6 & $\begin{array}{l}\text { Mass spectrum for the tentatively identified perfluorohexane found in the } 2 \text { min } \\
\text { TD sampler analyzed by GC-MS }\end{array}$ & 23 \\
\hline Figure S7 & $\begin{array}{l}\text { Mass spectrum for the tentatively identified (Perfluorohexyl)ethylene found in } \\
\text { the } 2 \text { min TD sampler analyzed by GC-MS }\end{array}$ & 24 \\
\hline Figure S8 & $\begin{array}{l}\text { Mass spectrum for the tentatively identified perfluorohexyl iodide found in the } \\
\qquad 2 \text { min TD sampler analyzed by GC-MS }\end{array}$ & 25 \\
\hline Figure S9A & $\begin{array}{c}\text { Mass spectrum for the tentatively identified 1H,1H,2H,2H-Perfluorooctyl } \\
\text { iodide found in the } 2 \text { min TD sampler analyzed by GC-MS }\end{array}$ & 26 \\
\hline Figure S9B & $\begin{array}{c}\text { Mass spectrum of } 1 \mathrm{H}, 1 \mathrm{H}, 2 \mathrm{H}, 2 \mathrm{H} \text {-Perfluorooctyl iodide standard in methanol at } \\
4.98 \mathrm{~min} \text { analyzed by GC-MS }\end{array}$ & 27 \\
\hline Figure S9C & $\begin{array}{l}\text { Mass spectrum of } 1 \mathrm{H}, 1 \mathrm{H}, 2 \mathrm{H}, 2 \mathrm{H} \text {-Perfluorooctyl iodide in AFFF headspace at } \\
\qquad 4.20 \mathrm{~min} \text { analyzed by GC-MS }\end{array}$ & 28 \\
\hline Figure S10A & $\begin{array}{l}\text { Mass spectrum for the tentatively identified tridecafluoro-1-iodooct-1-ene } \\
\text { found in the } 2 \text { min TD sampler analyzed by GC-MS }\end{array}$ & 29 \\
\hline Figure S10B & $\begin{array}{l}\text { Mass spectrum for tridecafluoro-1-iodooct-1-ene standard in methanol at } 4.15 \\
\text { min analyzed by GC-MS }\end{array}$ & 30 \\
\hline
\end{tabular}


Figure S11

Figure S12

Figure S13

Figure S14

Figure S15

Figure S16

Figure S17

Figure S18

Figure S19

Figure S20

Figure S21

Figure S22

Figure S23

Figure S24

Figure S25

Figure S26

Figure S27

Figure S28

Figure S29

Figure S30

Figure S31

Figure S32

Figure S33

Figure S34

Figure S35
Mass spectrum for unidentified PFAS at 8.102 min found in the 2 min TD sampler analyzed by GC-MS

Mass spectrum for unidentified PFAS at $10.291 \mathrm{~min}$ found in the $2 \mathrm{~min}$ TD sampler analyzed by GC-MS

Mass spectrum for unidentified PFAS at $14.904 \mathrm{~min}$ found in the $2 \mathrm{~min}$ TD sampler analyzed by GC-MS

Mass spectrum for unidentified PFAS at 15.537 min found in 2 min TD sampler analyzed by GC-MS

Mass spectrum and retention time for 4:2 FTOH standard injected into GC-MS 35

Mass spectrum and retention time for 5:2s FTOH standard injected into GCMS

Mass spectrum and retention time for 6:2 FTOH standard injected into GC-MS

Mass spectrum and retention time for 7:2s FTOH standard injected into GCMS

Mass spectrum and retention time for 8:2 FTOH standard injected into GC-MS

Mass spectrum and retention time for 10:2 FTOH standard injected into GCMS

Mass spectrum and retention time for PFUdA standard injected into GC-MS

Mass spectrum and retention time for PFTrDA standard injected into GC-MS 42

Mass spectrum and retention time for PFTeDA standard injected into GC-MS 43

Mass spectrum and retention time for PFPeA standard injected into GC-MS 44

Mass spectrum and retention time for PFODA standard injected into GC-MS $\quad 45$

Mass spectrum and retention time for PFNA standard injected into GC-MS 46

Mass spectrum and retention time for PFHxDA standard injected into GC-MS $\quad 47$

Mass spectrum and retention time for PFHxA standard injected into GC-MS $\quad 48$

Mass spectrum and retention time for PFHpA standard injected into GC-MS 49

Mass spectrum and retention time for PFDoA standard injected into GC-MS 50

Mass spectrum and retention time for PFDA standard injected into GC-MS 51

Mass spectrum and retention time for N-MeFOSE-M standard injected into 52

GC-MS

53

GC-MS

Mass spectrum and retention time for N-EtFOSE-M standard injected into GCMS

Mass spectrum and retention time for N-EtFOSA-M standard injected into GCMS 
Table S1. PFASs analytes and CAS number for TD-GC-MS analysis. All PFAS stocks were provided from Wellington Laboratories, Canada and the assay for each analyte was $>98 \%$.

27

\begin{tabular}{|c|c|c|}
\hline PFAS & Acronym & CAS \# \\
\hline Perfluorooctanoic acid & PFOA & $335-67-1$ \\
\hline Perfluorohexanoic acid & PFHxA & $307-24-4$ \\
\hline H,1H,2H,2H-Perfluoro-1-hexanol & $4: 2 \mathrm{FTOH}$ & $2043-47-2$ \\
\hline 1H,1H,2H,2H-Perfluoro-1-octanol & $6: 2 \mathrm{FTOH}$ & $647-42-7$ \\
\hline 1H,1H,2H,2H-Perfluoro-1-decanol & 8:2 FTOH & $678-39-7$ \\
\hline 1H,1H,2H,2H-Perfluoro-1-dodecanol & 10:2 FTOH & 865-86-1 \\
\hline 1H,1H,2H,2H-Perfluoroheptan-1-ol & $5: 2 \mathrm{sFTOH}$ & $185689-57-0$ \\
\hline 7:2 secondary fluorotelomer alcohols & $7: 2 \mathrm{sFTOH}$ & NA \\
\hline Perfluorooctadecanoic acid & PFODA & $16517-11-6$ \\
\hline Perfluorodecanoic acid & PFDA & $335-76-2$ \\
\hline Perfluoroheptanoic acid & PFHрA & $375-85-9$ \\
\hline Perfluorotetradecanoic acid & PFTeDA & $376-06-7$ \\
\hline Perfluoropentanoic acid & PFPeA & $2706-90-3$ \\
\hline Perfluorononanoic acid & PFNA & $375-95-1$ \\
\hline Perfluorododecanoic acid & PFDoA & $307-55-1$ \\
\hline Perfluorohexadecanoic acid & PFHxDA & $67905-19-5$ \\
\hline Perfluorotridecanoic acid & PFTrDA & 72629-94-8 \\
\hline Perfluoroundecanoic acid & PFUdA & 2058-94-8 \\
\hline N-Methyl-perfluorooctane-1-sulphonamide & N-MeFOSA-M & $31506-32-8$ \\
\hline N-Ethyl-perfluorooctane-sulfonamide & N-EtFOSA-M & $4151-50-2$ \\
\hline $\begin{array}{l}\text { N-Methyl-N-ethanol-perfluorooctane- } \\
\text { sulfonamide }\end{array}$ & N-MeFOSE-M & 24448-09-7 \\
\hline $\begin{array}{l}\text { N-Ethyl-N-(2- } \\
\text { hydroxyethyl)perfluorooctylsulphonamide }\end{array}$ & N-EtFOSE-M & $1691-99-2$ \\
\hline
\end{tabular}


Table S2. PFASs analytes and CAS number for XAD/PUF LC-MS/MS analysis. All PFAS stocks were provided from Wellington Laboratories, Canada and the assay for each analyte was $>98 \%$.

\begin{tabular}{|c|c|c|}
\hline PFAS & Acronym & CAS \# \\
\hline Perfluorohexanoic acid & PFHxA & $307-24-4$ \\
\hline 1H,1H,2H,2H-Perfluorooctanesulfonic acid & $6: 2$ FTS & 27619-97-2 \\
\hline Perfluorobutyric acid & PFBA & $375-22-4$ \\
\hline Perfluoropentanoic acid & PFPeA & $2706-90-3$ \\
\hline Perfluorobutanesulfonic acid & PFBS & $375-73-5$ \\
\hline 1H,1H,2H,2H-Perfluorohexanesulphonic acid & $4: 2$ FTS & 757124-72-4 \\
\hline Perfluoropentane-1-sulphonic acid & PFPeS & 2706-91-4 \\
\hline Perfluoroheptanoic acid & PFHрA & $375-85-9$ \\
\hline Perfluorohexanesulfonic acid & PFHxS & $355-46-4$ \\
\hline Perfluorooctanoic acid & PFOA & $335-67-1$ \\
\hline Perfluoroheptanesulfonic acid & PFHpS & $375-92-8$ \\
\hline Perfluorononanoic acid & PFNA & $375-95-1$ \\
\hline Perfluorooctanesulfonamide & PFOSA & $754-91-6$ \\
\hline Perfluorooctanesulfonic acid & PFOS & $1763-23-1$ \\
\hline Perfluorodecanoic acid & PFDA & $335-76-2$ \\
\hline 1H,1H,2H,2H-Perfluorodecanesulphonic acid & 8:2 FTS & 39108-34-4 \\
\hline Perfluorononanesulfonic acid & PFNS & $68259-12-1$ \\
\hline N-methylperfluorooctane sulfonamidoacetic acid & Me-FOSAA & 2355-31-9 \\
\hline N-ethylperfluorooctane sulfonamidoacetic acid & Et-FOSAA & 2991-50-6 \\
\hline Perfluoroundecanoic acid & PFUdA & 2058-94-8 \\
\hline Perfluorodecane sulfonic acid & PFDS & $335-77-3$ \\
\hline Perfluorooctadecanoic acid & PFODA & $16517-11-6$ \\
\hline N-Methyl-perfluorooctane-1-sulphonamide & N-MeFOSA-M & 31506-32-8 \\
\hline Perfluorotridecanoic acid & PFTrDA & 72629-94-8 \\
\hline Perfluorotetradecanoic acid & PFTeDA & 376-06-7 \\
\hline N-Ethyl-perfluorooctane-sulfonamide & N-EtFOSA-M & $4151-50-2$ \\
\hline Perfluorohexadecanoic acid & PFHxDA & $67905-19-5$ \\
\hline Perfluorooctadecanoic acid & PFODA & 16517-11-6 \\
\hline \multirow{2}{*}{$\begin{array}{l}\text { N-Methyl-N-ethanol-perfluorooctane-sulfonamide } \\
\text { N-Ethyl-N-(2-hydroxyethyl) perfluorooctyl- } \\
\text { sulphonamide }\end{array}$} & N-MeFOSE-M & 24448-09-7 \\
\hline & N-EtFOSE-M & $1691-99-2$ \\
\hline
\end{tabular}


Table S3. Typical physiochemical characteristics of C306-MS-C 3\% AFFF concentrate at $25{ }^{\circ} \mathrm{C}$, provided by manufacturer's datasheet.

Table S4. Chemical composition of C306-MS-C 3\% AFFF concentrate provided by manufacturer's datasheet.

\begin{tabular}{ccc}
\hline Chemical & CAS & Weight (\%) \\
\hline 2-(2-Butoxyethoxy)ethanol & $112-34-5$ & $10-30$ \\
Laurylamidopropyl betaine & $4292-10-8$ & $1-5$ \\
Caprylcaprilyl glucoside & $68515-73-1$ & $1-5$ \\
Polyfluorinated alkyl polyamide & Proprietary & $1-5$ \\
Octylphenoxypolyethoxyethanol & $9036-19-5$ & $1-5$ \\
Polyfluorinated alkyl quaternary amine chloride & Proprietary & $0.1-1$ \\
\hline
\end{tabular}

54

55 Relative humidity and temperature were monitored during the experiments using VelociCalc

Plus Multi-Parameter Ventilation Meter model 8384 (TSI Incorporation, MN, USA). The sensor

57 was suspended from the caps of AFFF chambers. Measurements were recorded immediately, 2

58 min and $1 \mathrm{hr}$ after AFFF agitation. 
Table S5. Experiments conducted above agitated AFFF to capture potential gas-phase PFASs

\begin{tabular}{ccccc}
\hline $\begin{array}{c}\text { Sampler } \\
\text { type }\end{array}$ & Experiment & Duration & $\begin{array}{c}\text { Number of } \\
\text { samplers }\end{array}$ & $\begin{array}{c}\text { Air } \\
\text { volume (L) }\end{array}$ \\
\hline \multirow{2}{*}{ TD tubes } & Immediately after AFFF Agitation & $2 \mathrm{~min}$ & 2 & 0.4 \\
& 1 hr after AFFF Agitation & $2 \mathrm{~min}$ & 2 & 0.4 \\
\multirow{3}{*}{ XAD/PUF } & Continuously after AFFF Agitation & $24 \mathrm{~h}$ & 2 & $288 \mathrm{~L}$ \\
& Immediately after AFFF Agitation & $60 \mathrm{~min}$ & 2 & $12 \mathrm{~L}$ \\
& Continuously after AFFF Agitation & $24 \mathrm{~h}$ & 2 & $288 \mathrm{~L}$ \\
\hline
\end{tabular}

61

62

63

64

65

66

67

68

69

70

71

Table S6. Relative humidity and temperature during experimental operation

\begin{tabular}{ccc}
\hline Samples & \% Relative Humidity & Temperature $^{\circ} \mathbf{F}$ \\
\hline Blanks & 85 & $72.4 \pm 1.2$ \\
\hline \multicolumn{3}{c}{ Immediately After Agitation } \\
XAD/PUFs & $84.4 \pm 1.0$ & $71.8 \pm 0.6$ \\
\hline \multicolumn{3}{c}{1 hour after agitation } \\
XAD/PUFs & $85.8 \pm 1.0$ & $71.2 \pm 0.5$ \\
\hline \multicolumn{3}{c}{ Room conditions } \\
\hline
\end{tabular}

\section{Analytical approach}

2.1 Experimental Setup

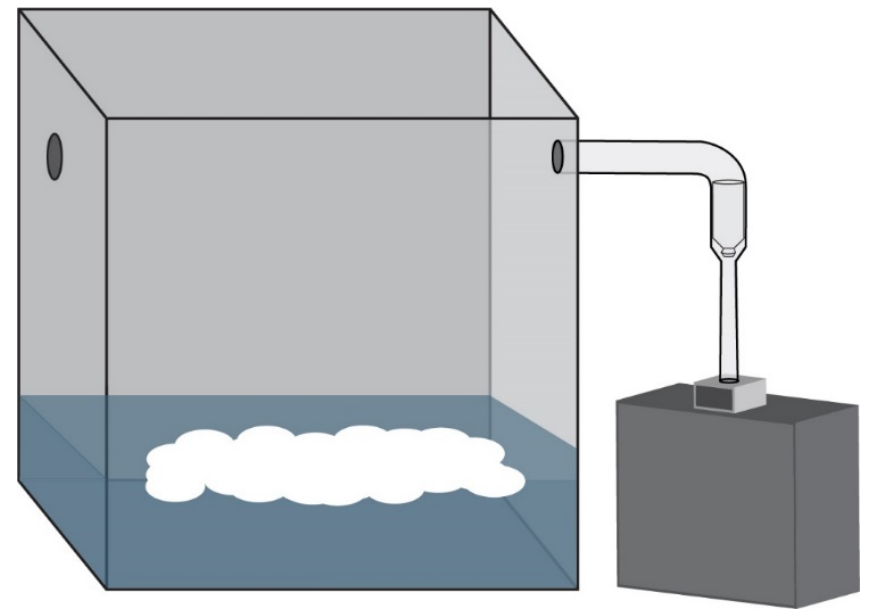

Figure S1. Schematic illustrating the AFFF chambers experimental setup 
75 C3-AAXX-5266 universal stainless-steel tubes (89 mm L., 6.4 mm O.D., 5 mm I.D.) from

76 Markes International, UK were used for air sampling. Each tube was filled with three sorbent

77 media including a porous polymer, fine grained graphitized carbon black, and a carbon

78 molecular sieve. Tubes have been thoroughly prepared and securely sealed before use. TD

79 samplers were stored capped at room temperature.

80

$81 \quad$ 2.2.2 Polyurethane foam air sampler

82 Glass open tubes (100 mm L., 22 mm O.D., 5 mm I.D., Air sampling Solutions and Expertise

83 SKC Inc., UK.) were filled with 4 gm of fine grained XAD-2 resin (Figure S2) between two

84 plugs of polyurethane foam (30 mm each). The samplers were pre-spiked with ${ }^{13} \mathrm{C}_{2}-4: 2$ FTS and

$85{ }^{13} \mathrm{C}_{3}$-PFOA before the experiment and placed in sealed polyethylene bags and stored in a

86 refrigerator at $4^{\circ} \mathrm{C}$ after the experiment, until the samples were shipped for analysis.

87

88

89

90

91

92 
Figure S2. XAD/Polyurethane foam air sampler diagram

$102 \quad 2.3$ Quantification of PFASs

103

2.3.1 GC-MS analysis of TD tubes

104

\subsubsection{Calibration method}

105 The analytical approach of TD samplers by GC-MS is similar to Wu et al. ${ }^{1} 34$ individual PFASs standards (50 ng/ $\mu \mathrm{L}$ in methanol each, Tables S1, S2) were initially tested for quantification by

107 TD-GC-MS. A calibration solution loading rig (CSLR, Markes International, UK) was used to 108 introduce analytes standards to TD tubes. To ensure that analytes were well retained by the TD 109 sorbent bed, helium carrier gas was set at $50 \mathrm{ml} / \mathrm{min}$ for $1 \mathrm{~min}$ to purge any solvent from inside 110 the tubes. While the carrier gas is still flowing, $1 \mu$ l of each analyte was introduced to TD tubes 111 using standard precision GC syringe. Immediately after injection, the methanol solvent vaporized 112 in the carrier gas flow and the analytes reached the TD sorbent media at vapor-phase. 22 PFASs 113 (Table S1) had discernable peaks using TD-GC-MS (Figures S15-S35). The 22 PFASs were 
114 mixed to create standard mix at $2.2 \mathrm{ng} / \mu \mathrm{L}$ in methanol for breakthrough and recovery

115 experiments.

$116 \quad$ 2.3.1.2 Instrumental analysis

117 Desorption of analytes from TD tubes was conducted using TD100-xr (Markes International, 118 UK) high performance thermal desorber. The TD100-xr was connected directly to GC-MS via 119 heated and deactivated transfer line made of silica. The gas chromatography (Thermo Scientific 120 GC 1310, MA, USA) was in conjunction with mass spectrometer (Thermo Scientific MS ISQ 121 7000, MA, USA) that was operated in positive electron ionization mode (EI+). Desorption of 122 analytes from the TD tubes were conducted by introducing heated carrier gas at $300{ }^{\circ} \mathrm{C}$ for 8 min 123 at $75 \mathrm{ml} / \mathrm{min}$ flowrate. Desorbed analytes were refocused into two sorbent-packed cold-trapping 124 systems including a materials emissions trap (U-12ME-2S) and air toxics trap (U-T15ATA-2S) 125 to ensure maximum capture of analytes. The re-focused analytes were released from the traps 126 using rapid heating cycle at $100{ }^{\circ} \mathrm{C} /$ second starting at 25 to $300{ }^{\circ} \mathrm{C}$ for $4 \mathrm{~min}$ at $6 \mathrm{ml} / \mathrm{min}$ 127 flowrate. The heated gas stream was introduced to GC-MS through the silica-transfer line for 128 further analysis.

129 Analytes were separated using GC column DB-VRX (60 m L., 0.25 mm I.D., $1.4 \mu \mathrm{m}$ film 130 thickness, Agilent Technologies Inc. CA, USA). Helium gas was used as the carrier gas at 1.2 $131 \mathrm{ml} / \mathrm{min}$ constant flowrate. GC temperature program was set on $35^{\circ} \mathrm{C}$ for $5 \mathrm{~min}$ followed by 10

$132{ }^{\circ} \mathrm{C}$ increase per minute until $230{ }^{\circ} \mathrm{C}$ for $15 \mathrm{~min}$. The MS was operated in scan mode to facilitate 133 the simultaneous quantification of targeted analytes and non-target compounds. Analytes were 134 quantified using area integration of two to three targeted fragment ions determined from 135 injections of analytical standards. 
137 Appropriate gas sampling volumes were determined using breakthrough tests. Three TD Markes 138 universal tubes (C3-AAXX-5266) were coupled in parallel and loaded with 2200 pg of 22 139 PFASs mixture. Flowrate was fixed at $200 \mathrm{ml} / \mathrm{min}$ with varying sampling periods for 2 (400 mL) 140 and 4 min $(800 \mathrm{~mL})$. The same conditions were utilized to test PFAS recovery rates using Tenax 141 TA TD tubes in addition to C3-AAXX-5266 stainless steel TD tubes. The tests were performed 142 in triplicates using the 22 PFASs standard mix at spiking level of $2200 \mathrm{pg}$. The spiked tubes were 143 treated like real samples and quantification of each PFASs was conducted using a six point 144 calibration curve. Blank experiments were also conducted including instrumental and sorbent 145 blanks and the analysis were carried out by conditioning and analyzing the TD tubes with and 146 without adsorbents. The blank samples were treated the same as other samples with AFFF 147 present.

148 The recovery rates for all PFAS were greater than $90 \%$ for both air volumes tested except for 149 PFoDA (83 and 72\% for 400 and $800 \mathrm{~mL}$, respectively). Because the recovery was generally 150 high and because it is difficult to spike labeled standards to a TD sampler, no correction was 151 conducted for analyte losses. Moreover, all PFAS exhibited less than 5\% carryover in the 152 breakthrough experiments except for PFDoA. Based on these data, $400 \mathrm{~mL}$ was selected as the 153 sampling volume for the further experiments

154 Six different PFASs concentrations between 1.1 and $100 \mu \mathrm{g} / \mathrm{m}^{3}$ were used to determine the 155 linearity of each PFAS calibration curve. Repeatability of 13.2\% was achieved and determined 156 by relative standard deviation (RSD\%) of triplicate samples with spike of $1 \mu$ of individual 157 PFAS standard. Based on these data, the limit of detection for the 22 PFASs was determined at $158 \quad 0.1 \mu \mathrm{g} / \mathrm{m}^{3}$ for a $400 \mathrm{~mL}$ sampling volume. 
160 The separation, identification and quantification of 30 targeted PFASs (Table S2) was conducted 161 by Vista Analytical Laboratories based in El Dorado Hills, California. XAD/PUF samplers were 162 extracted with methanol, spiked with mass labeled internal standards, evaporated to $1 \mathrm{~mL}$ and 2 $163 \mu \mathrm{L}$ directly injected into a LC-MS/MS in multiple reaction monitoring mode. Recovery rates for 164 the labeled PFASs internal standards ranged between 58 and $110 \%$. Prior to the experiments, 165 XAD resin was conditioned and pre-cleaned with acetone, MTBE, methanol and finally Hexane 166 to ensure removal of any background contamination and water. Additionally, quality control 167 samples were conducted by direct injection of PFASs dissolved in methanol at $50 \mathrm{ng} / \mathrm{ml}$ into LC168 MS/MS, and the recovery rates were 77 to 113\%. The LC-MS/MS method complied with DoD 169 ELAP QSM Table B-15 of v 5.1.

170 The LC-MS/MS reporting limits were $\leq 0.5 \mu \mathrm{g} / \mathrm{L}$ in the methanol extract, which is equivalent to 171 approximately $42 \mathrm{ng} / \mathrm{m}^{3}$ and $2 \mathrm{ng} / \mathrm{m}^{3}$ for $1 \mathrm{hr}$ and 24 hour experiments, respectively, based on the 172 assumption of $100 \%$ recovery from the resin. Note that for the XAD/PUF samplers, other than $173{ }^{13} \mathrm{C}_{2}-4: 2$ FTS and ${ }^{13} \mathrm{C}_{3}$-PFOA, the mass labeled surrogates were spiked to the extract and 174 therefore do not account for extraction losses, meaning the values reported here represent the 175 minimum gas phase concentration. ${ }^{13} \mathrm{C}_{2}-4: 2$ FTS and ${ }^{13} \mathrm{C}_{3}-\mathrm{PFOA}$ were spiked to the sampler 176 before the experiment, other isotopically labeled surrogates were spiked to the methanol extract 177 before drying.

179 Confirmation of Markes' putative identifications was conducted in-house by gentle inversion of 180 a $40 \mathrm{~mL} \mathrm{1:1} \mathrm{dilution} \mathrm{of} \mathrm{AFFF} \mathrm{for} 2 \mathrm{~min}$ and injection of the headspace into a Waters Quatro 
181 Micro GC. Identified matches of spectra observed by the in-house method and by the Markes TD

182 analysis were purchased as neat analytical standards, diluted into dichloromethane, and retention

183 time and fragmentation was confirmed on the Waters Quatro Micro GC instrument (i.e., spectral

184 matches were first confirmed between Markes and the in-house instrument, followed by

185 purchasing a neat standard for confirmation again of spectra and also retention time on the in-

186 house instrument).

187 PFASs standards were analyzed using a Waters Quattro Micro GC that was operated in positive 188 electron ionization mode (EI+). PFASs were loaded to a GC capillary column (SH-Rxi-5Sil MS

18930 m L., 0.25 mm I.D., $0.25 \mu$ m film thickness, Shimadzu Corp, Kyoto, Japan) using an

190 autosampler and GC injector (7683 series, Agilent Technologies Inc. CA, USA). Helium gas was

191 used as carrier gas starting at $1.9 \mathrm{ml} / \mathrm{min}$ and instantly decreasing to $1.3 \mathrm{ml} / \mathrm{min}$ upon injection.

$192 \mathrm{GC}$ temperature program was $60{ }^{\circ} \mathrm{C}$ for $2 \mathrm{~min}$ followed by $3{ }^{\circ} \mathrm{C}$ increase per minute until $75^{\circ} \mathrm{C}$

193 for 2 min, followed by $20^{\circ} \mathrm{C}$ increase per minute for $10 \mathrm{~min}$ until $250{ }^{\circ} \mathrm{C}$. The MS was operated

194 in scan mode from 25 to $350 \mathrm{~m} / \mathrm{z}$.

195 3. Discussion

1963.1 Analysis of volatile FTOHs in AFFFs headspace

197 In Riedel et $\mathrm{al}^{2}$ study, volatile FTOHs were detected in the headspace of Arctic U.S. type 3 (3\%)

198 MIL-SPEC AFFF Foam including 8:2 and 6:2 FTOH at 0.3 and $1.6 \mathrm{ng} / \mu \mathrm{L}$ of AFFF,

199 respectively. The sampling flowrate was fixed at $500 \mathrm{ml} / \mathrm{min}$ for $\sim 1 \mathrm{~h}$ while varying AFFF

200 volume between $20-500 \mu \mathrm{L}$. The headspace air was directly injected into the inlet of the A high

201 resolution time-of-flight chemical ionization mass spectrometer (CIMS) for FTOHs analysis. In

202 our analysis, we reported the detection variety groups of primary and secondary FTOHs 
203 including 4:2, 6:2, 10:2 FTOH, 7:2, and 5:2 sFTOH at 38.1, 35.1, 9.8, 10.2 and $1.1 \mu \mathrm{g} / \mathrm{m}^{3}$,

204 respectively. 8:2 FTOH was not present in our samples and the 6:2 FTOH was at low

205 concentrations in contrast with Riedel et al study. This might be attributed to the different types

206 of AFFF used in each study in addition to the use of higher sampling duration and flowrate

207 accumulating total volume of headspace injected to CIMS of 30,000 mL in contrast of $400 \mathrm{~mL}$ in

208 our study. Furthermore, the authors reported the concentration based on volume of the AFFF

209 rather than the volume of gas sampled, making it difficult to assess potential exposure comparing

210 to our analysis.

2113.2 Impact of site competition on PFASs sorption by XAD/PUF

212 The high concentration of other non-fluorinated organic compounds (see Non-targeted

213 compounds for further discussion) may have substantially reduced PFASs sorption; XAD/PUF

214 samplers are well known to sorb a wide range of semi-volatile and volatile organic compounds,

215 which compete for sorption sites. ${ }^{3}$ Additionally, XAD/PUF samplers were exposed to between

21630 and 720 times more gas volume than TD tubes during the experiments. Thus, they might have

217 been over saturated with SVOCs present in AFFF headspace (Table S10), leading to reduction in

218 PFASs sorption. A recent article supports this, where non-fluorinated organic compounds present

219 in AFFF concentrates reduced PFAS sorption to soil in the aqueous phase. ${ }^{4}$ Therefore, we expect

220 similar behavior might occurred in the gas-phase. Furthermore, in section 3.3, we exposed TD

221 tubes into AFFF headspace for 24 h continuously in an effort to capture as many PFASs as

222 possible. The samplers were severely overloaded with VOCs, which saturated the GC column

223 and detector. We then conducted a second sampling to correct this at a much shorter duration. 
225 Table S7. PFASs concentrations sampled by TD samplers immediately and $1 \mathrm{~h}$ after AFFF 226 agitation

\begin{tabular}{|c|c|c|c|c|}
\hline PFAS & $\begin{array}{l}\text { Molecular } \\
\text { Formula }\end{array}$ & $\begin{array}{c}\text { Control/blank } \\
\left(\mu g / \mathrm{m}^{3}\right)\end{array}$ & $\begin{array}{c}\text { Immediately After AFFF } \\
\text { Agitation }\left(\mu \mathrm{g} / \mathrm{m}^{3}\right)^{*}\end{array}$ & $\begin{array}{c}\text { 1h After AFFF } \\
\text { Agitation }\left(\mu \mathrm{g} / \mathrm{m}^{3}\right)^{*}\end{array}$ \\
\hline PFOA & $\mathrm{C}_{8} \mathrm{HF}_{15} \mathrm{O}_{2}$ & 1.7 & $8121 \pm 1262$ & $13670 \pm 1797$ \\
\hline PFHxA & $\mathrm{C}_{6} \mathrm{HF}_{11} \mathrm{O}_{2}$ & - & $127.1 \pm 38.6$ & $183.5 \pm 4.7$ \\
\hline $4: 2$ FTOH & $\mathrm{C}_{6} \mathrm{H}_{5} \mathrm{~F}_{9} \mathrm{O}$ & 4.8 & $36.3 \pm 7.5$ & $42.9 \pm 2.4$ \\
\hline 6:2 FTOH & $\mathrm{C}_{8} \mathrm{H}_{5} \mathrm{~F}_{13} \mathrm{O}$ & - & $33.5 \pm 0.4$ & $35.1 \pm 0.8$ \\
\hline PFDA & $\mathrm{C}_{10} \mathrm{HF}_{19} \mathrm{O}_{2}$ & 0.1 & $27.0 \pm 9.6$ & $58.5 \pm 3.0$ \\
\hline 10:2 FTOH & $\mathrm{C}_{12} \mathrm{H}_{5} \mathrm{~F}_{21} \mathrm{O}$ & 1.4 & $10.8 \pm 1.5$ & $11.2 \pm 0.5$ \\
\hline 7:2 sFTOH & $\mathrm{C}_{9} \mathrm{H}_{5} \mathrm{~F}_{15} \mathrm{O}$ & 0.1 & $5.8 \pm 1.7$ & $10.3 \pm 0.6$ \\
\hline PFHрA & $\mathrm{C}_{7} \mathrm{HF}_{13} \mathrm{O}_{2}$ & 0.1 & $4.5 \pm 1.8$ & $12.5 \pm 4.2$ \\
\hline PFTeDA & $\mathrm{C}_{14} \mathrm{HF}_{27} \mathrm{O}_{2}$ & - & $2.8 \pm 1.0$ & $7.7 \pm 2.4$ \\
\hline PFPeA & $\mathrm{C}_{5} \mathrm{HF}_{9} \mathrm{O}_{2}$ & - & $1.5 \pm 0.5$ & $3.0 \pm 1.0$ \\
\hline PFNA & $\mathrm{C}_{9} \mathrm{HF}_{17} \mathrm{O}_{2}$ & 0.1 & $1.1 \pm 0.6$ & - \\
\hline PFDoA & $\mathrm{C}_{12} \mathrm{HF}_{23} \mathrm{O}_{2}$ & - & $1.1 \pm 0.5$ & $3.0 \pm 0.2$ \\
\hline PFHxDA & $\mathrm{C}_{16} \mathrm{HF}_{31} \mathrm{O}_{2}$ & - & $0.8 \pm 0.3$ & $1.2 \pm 0.1$ \\
\hline $5: 2 \mathrm{sFTOH}$ & $\mathrm{C}_{7} \mathrm{H}_{5} \mathrm{~F}_{11} \mathrm{O}$ & - & $0.5 \pm 0.1$ & $1.1 \pm 0.1$ \\
\hline PFTrDA & $\mathrm{C}_{13} \mathrm{HF}_{25} \mathrm{O}_{2}$ & - & $0.4 \pm 0.1$ & - \\
\hline PFUdA & $\mathrm{C}_{11} \mathrm{HF}_{21} \mathrm{O}_{2}$ & 0.5 & - & - \\
\hline N-MeFOSA-M & $\mathrm{C}_{9} \mathrm{H}_{4} \mathrm{~F}_{17} \mathrm{NO}_{2} \mathrm{~S}$ & 0.9 & $0.2 \pm 0.1$ & $0.2 \pm 0.1$ \\
\hline N-EtFOSA-M & $\mathrm{C}_{10} \mathrm{H}_{6} \mathrm{~F}_{17} \mathrm{NO}_{2} \mathrm{~S}$ & 2.9 & $0.2 \pm 0.1$ & $0.1 \pm 0.1$ \\
\hline N-MeFOSE-M & $\mathrm{C}_{11} \mathrm{H}_{8} \mathrm{~F}_{17} \mathrm{NO}_{3} \mathrm{~S}$ & 0.4 & - & - \\
\hline PFODA & $\mathrm{C}_{18} \mathrm{HF}_{35} \mathrm{O}_{2}$ & - & - & - \\
\hline 8:2 FTOH & $\mathrm{C}_{10} \mathrm{H}_{5} \mathrm{~F}_{17} \mathrm{O}$ & - & - & - \\
\hline
\end{tabular}

a. Control samples were continuously exposed for $1 \mathrm{~h}$ to the headspace air of PFASs-free certified water.

b. * Results shown represent total PFASs concentration without subtraction of control values or adjustment for recovery 

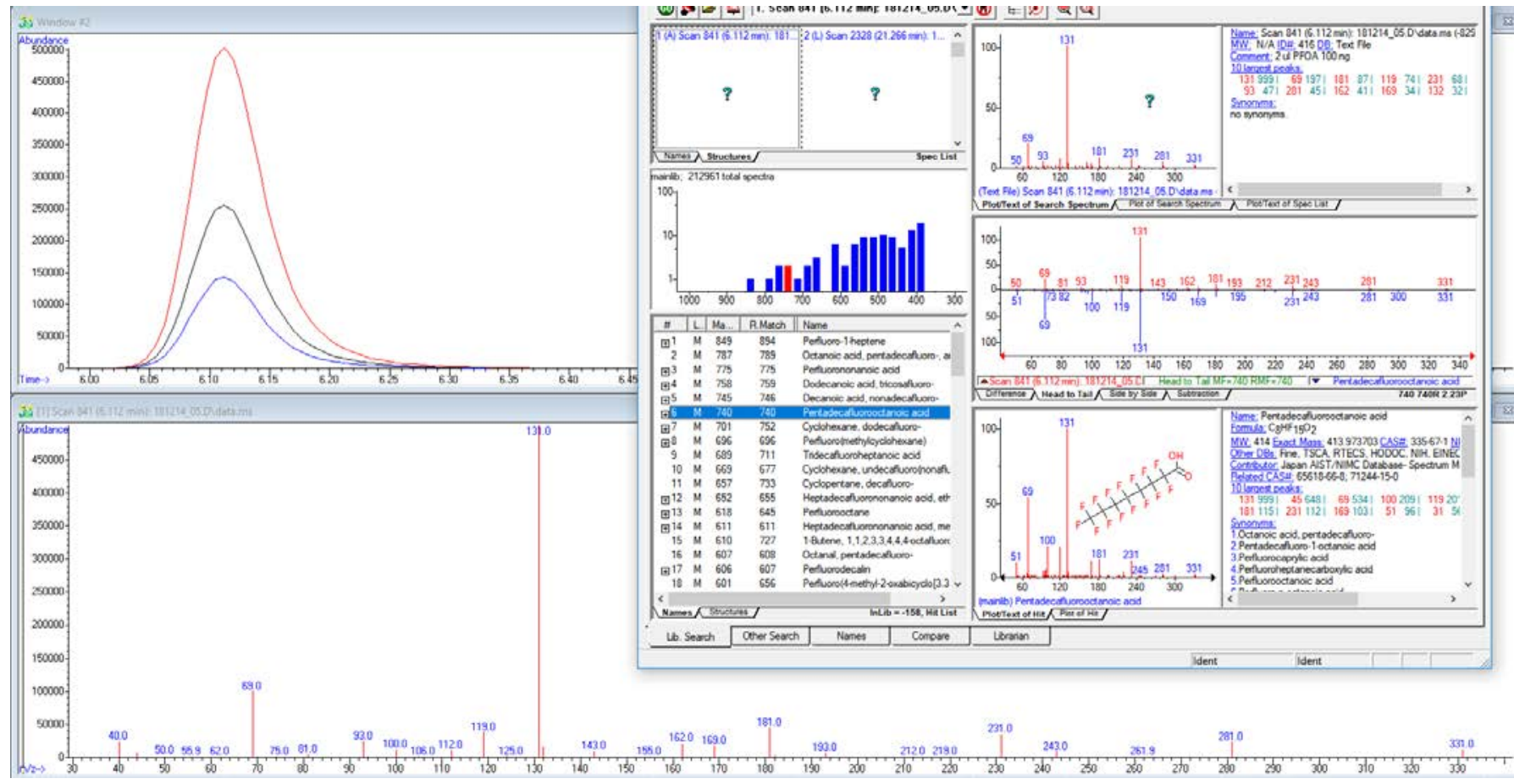

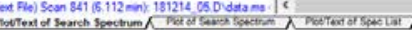

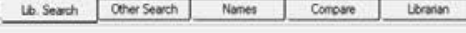

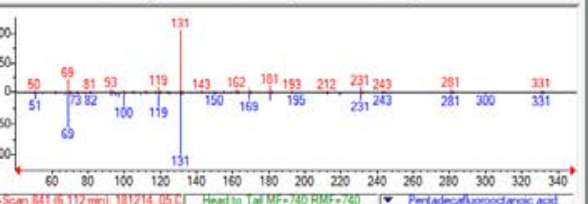

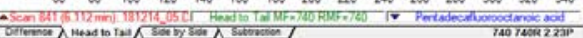

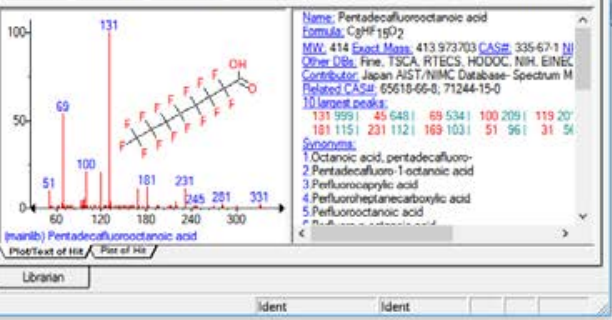


Table S8. PFASs concentrations sampled by XAD/PUF samplers after continuously sampling the AFFF headspace gas for 1 and $24 \mathrm{~h}$

\begin{tabular}{|c|c|c|c|c|}
\hline PFAS & $\begin{array}{c}\text { Molecular } \\
\text { Formula }\end{array}$ & $\begin{array}{c}\text { Control/blank } \\
\left(\mu \mathrm{g} / \mathrm{m}^{3}\right)\end{array}$ & $1 \mathrm{~h}\left(\mu \mathrm{g} / \mathrm{m}^{3}\right)$ & $24 \mathrm{~h}\left(\mu \mathrm{g} / \mathrm{m}^{3}\right)$ \\
\hline PFHxA & $\mathrm{C}_{6} \mathrm{HF}_{11} \mathrm{O}_{2}$ & - & - & $37.4 \pm 6.2$ \\
\hline 6:2 FTS & $\mathrm{C}_{8} \mathrm{H}_{5} \mathrm{~F}_{13} \mathrm{O}_{3} \mathrm{~S}$ & - & $2.3 \pm 0.6$ & $72.1 \pm 7.6$ \\
\hline PFBA & $\mathrm{C}_{4} \mathrm{HF}_{7} \mathrm{O}_{2}$ & 3.2 & $4.7 \pm 1.0$ & $2.7 \pm 0.2$ \\
\hline PFPeA & $\mathrm{C}_{5} \mathrm{HF}_{9} \mathrm{O}_{2}$ & - & - & - \\
\hline PFBS & $\mathrm{C}_{4} \mathrm{HF}_{9} \mathrm{O}_{3} \mathrm{~S}$ & - & - & - \\
\hline 4:2 FTS & $\mathrm{C}_{6} \mathrm{H}_{5} \mathrm{~F}_{9} \mathrm{O}_{3} \mathrm{~S}$ & - & - & - \\
\hline PFPeS & $\mathrm{C}_{5} \mathrm{HF}_{11} \mathrm{O}_{3} \mathrm{~S}$ & - & - & - \\
\hline PFHpA & $\mathrm{C}_{7} \mathrm{HFF}_{13} \mathrm{O}_{2}$ & - & - & - \\
\hline PFHxS & $\mathrm{C}_{6} \mathrm{HF}_{13} \mathrm{O}_{3} \mathrm{~S}$ & - & - & - \\
\hline PFOA & $\mathrm{C}_{8} \mathrm{HF}_{15} \mathrm{O}_{2}$ & - & - & - \\
\hline PFHpS & $\mathrm{C}_{7} \mathrm{HF}_{15} \mathrm{O}_{3} \mathrm{~S}$ & - & - & - \\
\hline PFNA & $\mathrm{C}_{9} \mathrm{HF}_{17} \mathrm{O}_{2}$ & - & - & - \\
\hline PFOSA & $\mathrm{C}_{8} \mathrm{H}_{2} \mathrm{~F}_{17} \mathrm{NO}_{2} \mathrm{~S}$ & - & - & - \\
\hline PFOS & $\mathrm{C}_{8} \mathrm{HF}_{17} \mathrm{O}_{3} \mathrm{~S}$ & - & - & - \\
\hline PFDA & $\mathrm{C}_{10} \mathrm{HF}_{19} \mathrm{O}_{2}$ & - & - & - \\
\hline 8:2 FTS & $\mathrm{C}_{10} \mathrm{H}_{5} \mathrm{~F}_{17} \mathrm{O}_{3} \mathrm{~S}$ & - & - & - \\
\hline PFNS & $\mathrm{C}_{9} \mathrm{HF}_{19} \mathrm{O}_{3} \mathrm{~S}$ & - & - & - \\
\hline Me-FOSAA & $\mathrm{C}_{11} \mathrm{H}_{6} \mathrm{~F}_{17} \mathrm{NO}_{4} \mathrm{~S}$ & - & - & - \\
\hline Et-FOSAA & $\mathrm{C}_{12} \mathrm{H}_{8} \mathrm{~F}_{17} \mathrm{NO}_{4} \mathrm{~S}$ & - & - & - \\
\hline PFUdA & $\mathrm{C}_{11} \mathrm{HF}_{21} \mathrm{O}_{2}$ & - & - & - \\
\hline PFDS & $\mathrm{C}_{10} \mathrm{HF}_{21} \mathrm{O}_{3} \mathrm{~S}$ & - & - & - \\
\hline PFDoA & $\mathrm{C}_{12} \mathrm{HF}_{23} \mathrm{O}_{2}$ & - & - & - \\
\hline N-MeFOSA-M & $\mathrm{C}_{9} \mathrm{H}_{4} \mathrm{~F}_{17} \mathrm{NO}_{2} \mathrm{~S}$ & - & - & - \\
\hline PFTrDA & $\mathrm{C}_{13} \mathrm{HF}_{25} \mathrm{O}_{2}$ & - & - & - \\
\hline PFTeDA & $\mathrm{C}_{14} \mathrm{HF}_{27} \mathrm{O}_{2}$ & - & - & - \\
\hline N-EtFOSA-M & $\mathrm{C}_{10} \mathrm{H}_{6} \mathrm{~F}_{17} \mathrm{NO}_{2} \mathrm{~S}$ & - & - & - \\
\hline PFHxDA & $\mathrm{C}_{16} \mathrm{HF}_{31} \mathrm{O}_{2}$ & - & - & - \\
\hline PFODA & $\mathrm{C}_{18} \mathrm{HF}_{35} \mathrm{O}_{2}$ & - & - & - \\
\hline N-MeFOSE-M & $\mathrm{C}_{11} \mathrm{H}_{8} \mathrm{~F}_{17} \mathrm{NO}_{3} \mathrm{~S}$ & - & - & - \\
\hline Et-FOSE & $\mathrm{C}_{12} \mathrm{H}_{10} \mathrm{~F}_{17} \mathrm{NO}_{3} \mathrm{~S}$ & - & - & - \\
\hline
\end{tabular}

a. XAD/PUF samplers were continuously exposed for $60 \mathrm{~min}$ and $24 \mathrm{~h}$ to the headspace air of $1: 1$ AFFF to water

b. Estimated standard deviation were calculated based on duplicate samples for each PFAS 
Table S9. Estimated vapor concentrations for selected PFASs

\begin{tabular}{ccccc}
\hline Acronym & MW & $\begin{array}{c}\text { Vapor } \\
\text { Pressure [Pa] }\end{array}$ & $\begin{array}{c}\text { Estimated Vapor } \\
\text { Concentration }\left(\boldsymbol{\mu g} / \mathbf{m}^{3}\right)^{\mathbf{a}}\end{array}$ & $\begin{array}{c}\text { Vapor Pressure } \\
\text { Reference }\end{array}$ \\
\hline PFBA & 214.04 & 850 & $7.5 \mathrm{E}+07$ & 5 \\
PFHxA & 314.05 & 121 & $1.6 \mathrm{E}+07$ & 5 \\
PFHpA & 364.06 & 73 & $1.1 \mathrm{E}+07$ & 5 \\
PFOA & 414.07 & 70 & $1.2 \mathrm{E}+07$ & 6 \\
PFNA & 464.08 & 1.3 & $2.5 \mathrm{E}+05$ & 7 \\
PFDA & 514.09 & 0.2 & $4.9 \mathrm{E}+04$ & 7 \\
PFUnA & 564.09 & 0.1 & $2.3 \mathrm{E}+04$ & 6 \\
PFOS & 500.13 & 0.3 & $5.5 \mathrm{E}+04$ & 8 \\
N-MeFOSE-M & 557.22 & 0.0004 & $9.1 \mathrm{E}+01$ & 8 \\
N-EtFOSE-M & 571.25 & 0.002 & $4.7 \mathrm{E}+02$ & 9,10 \\
N-EtFOSA-M & 527.2 & 0.00006 & $1.2 \mathrm{E}+01$ & 9,10 \\
4:2 FTOH & 264.09 & 214 & $2.3 \mathrm{E}+07$ & 9,10 \\
6:2 FTOH & 364.11 & 18.2 & $2.7 \mathrm{E}+06$ & 9,10 \\
8:2 FTOH & 464.12 & 3.98 & $7.6 \mathrm{E}+05$ & 8 \\
10:2 FTOH & 564.14 & 0.2 & $4.6 \mathrm{E}+04$ & \\
\hline
\end{tabular}

a. Estimated vapor concentration at $20{ }^{\circ} \mathrm{C}=(\mathrm{MW}$ x Vapor pressure $) / \mathrm{RT}$

b. Use of vapor pressures to estimate vapor concentrations assumes PFASs are present in their pure forms. This assumption may not apply to all PFASs present in the AFFF used (e.g., PFOA).

PFOA dimensionless Henry’s constants:

- $\quad$ 1.02E-3 (Reference $\left.{ }^{11}\right)$

- $\quad 2.475 \mathrm{E}-4$ (Reference $\left.^{12}\right)$

- $1.25 \mathrm{E}-4$ (Reference $^{12}$ )

Dimensionless Henry's constant $=$ Concentration in air/ Concentration in water pKa Values:

$$
\begin{array}{ll}
- & \left.1.3 \text { (Reference }^{12}\right) \\
- & \left.2.5 \text { Reference }^{5}\right) \\
- & \left.2.8 \text { Reference }^{12}\right) \\
- & \left.3.8 \text { Reference }^{13}\right)
\end{array}
$$

$\mathrm{pH}$ of AFFF used = 7.6. Based on equilibrium calculations, $\mathrm{pKa}$ and $\mathrm{pH}$ :

$$
\text { 5.01186E-07 to 1.58464E-04 (\%) is neutral PFOA }
$$


Table S10. Tentatively identified hydrocarbons from TD sampler after sampling AFFF headspace for $2 \mathrm{~min}$

\begin{tabular}{|c|c|c|}
\hline Compound & $\begin{array}{l}\text { Retention } \\
\text { Time (min) }\end{array}$ & CAS No. \\
\hline 2-Propanol, 2-methyl- & 8.97 & $75-65-0$ \\
\hline Butanal & 11.12 & $123-72-8$ \\
\hline 1-Propanol, 2-methyl- & 11.99 & 78-83-1 \\
\hline 2,4-Hexadiene & 12.72 & $592-46-1$ \\
\hline 1,4-Dioxane & 13.1 & $71-36-3$ \\
\hline n-Propyl acetate & 14.57 & $123-91-1$ \\
\hline 2,4-Dimethylfuran & 14.59 & $109-60-4$ \\
\hline Butanenitrile, 2-methyl- & 14.78 & $3710-43-8$ \\
\hline Methyl Isobutyl Ketone & 14.98 & 18936-17-9 \\
\hline Toluene & 15.45 & 108-10-1 \\
\hline 2-Methyl-2-butenenitrile & 16.35 & $108-88-3$ \\
\hline 1,4-Dioxane, 2,5-dimethyl- & 16.4 & 4403-61-6 \\
\hline 3-Penten-2-one, 4-methyl- & 16.82 & $16529-56-9$ \\
\hline 1,4-Dioxane, 2,5-dimethyl- & 16.94 & $15176-21-3$ \\
\hline 20-Carboethoxy-20-demethylvincadifformine & 16.97 & 141-79-7 \\
\hline 1,4-Dioxane, 2,5-dimethyl- & 17.07 & $15176-21-3$ \\
\hline Ethanol, 2-iodo- & 17.6 & 112496-64-7 \\
\hline Ethylbenzene & 18 & $15176-21-3$ \\
\hline Benzene, 1,3-dimethyl- & 18.53 & 624-76-0 \\
\hline o-Xylene & 18.8 & $100-41-4$ \\
\hline Hexylene glycol & 19.35 & $108-38-3$ \\
\hline 4-Heptanone, 2,6-dimethyl- & 19.46 & $106-42-3$ \\
\hline Benzaldehyde & 20.56 & $108-38-3$ \\
\hline Benzene, 1,2,4-trimethyl- & 20.73 & $95-47-6$ \\
\hline Benzofuran & 21.4 & $107-41-5$ \\
\hline 2-Hexen-1-ol, 2-ethyl- & 21.55 & $108-83-8$ \\
\hline o-Cymene & 21.59 & 7492-38-8 \\
\hline 1-Octanol & 21.8 & $100-52-7$ \\
\hline Pentanoic acid, butyl ester & 22.13 & $95-63-6$ \\
\hline Benzene, 1-methyl-4-propyl- & 22.54 & $108-67-8$ \\
\hline Cyclopentasiloxane, decamethyl- & 22.65 & 271-89-6 \\
\hline 2-Butenoic acid, 2-methyl-, 2-methylpropyl ester, (E)- & 23.13 & $50639-00-4$ \\
\hline Benzene, 1,2,3,5-tetramethyl- & 23.48 & 527-84-4 \\
\hline Tetradecane, 4-methyl- & 23.75 & $535-77-3$ \\
\hline Naphthalene, 2-methyl- & 27.64 & $111-87-5$ \\
\hline 2-Propanol, 2-methyl- & 28.09 & $591-68-4$ \\
\hline
\end{tabular}




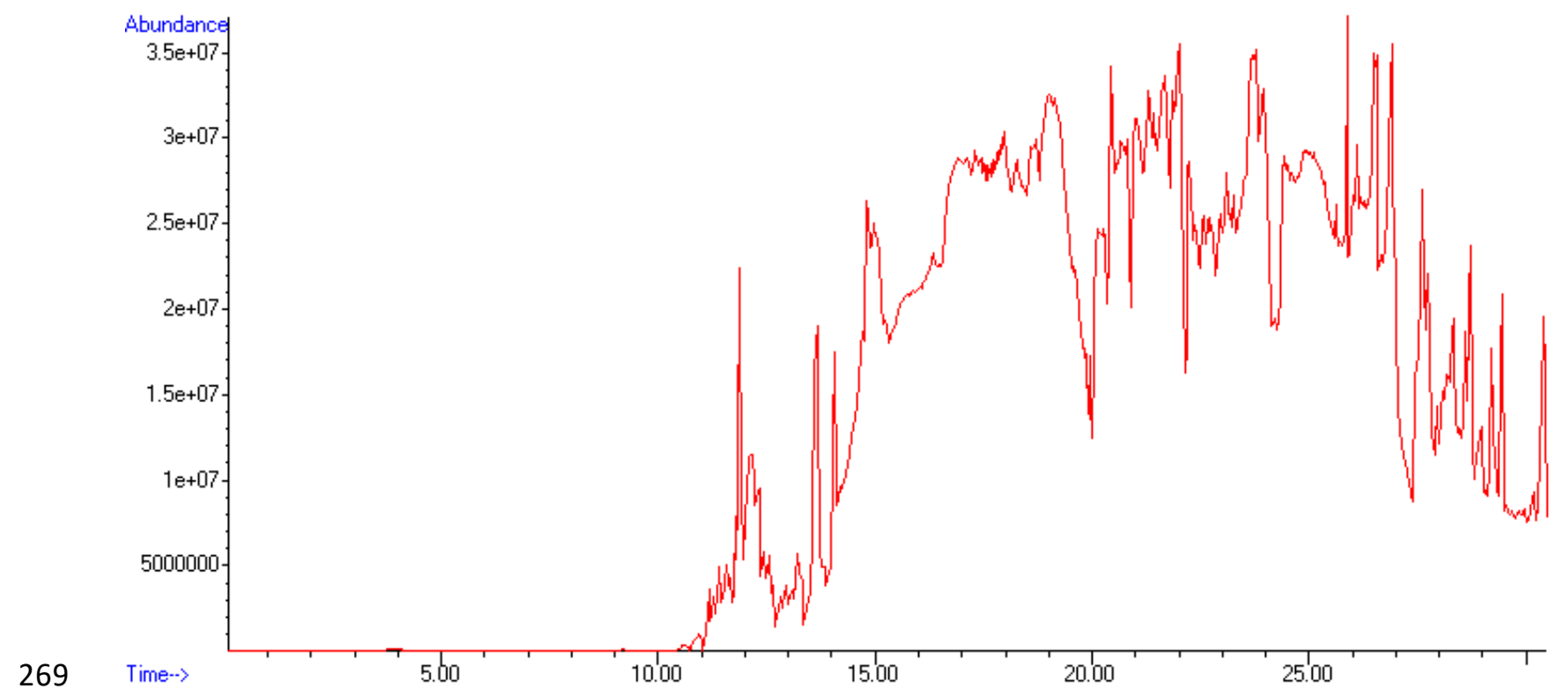

Figure S4. GC-MS total ion chromatogram of TD sampler after sampling AFFF headspace for

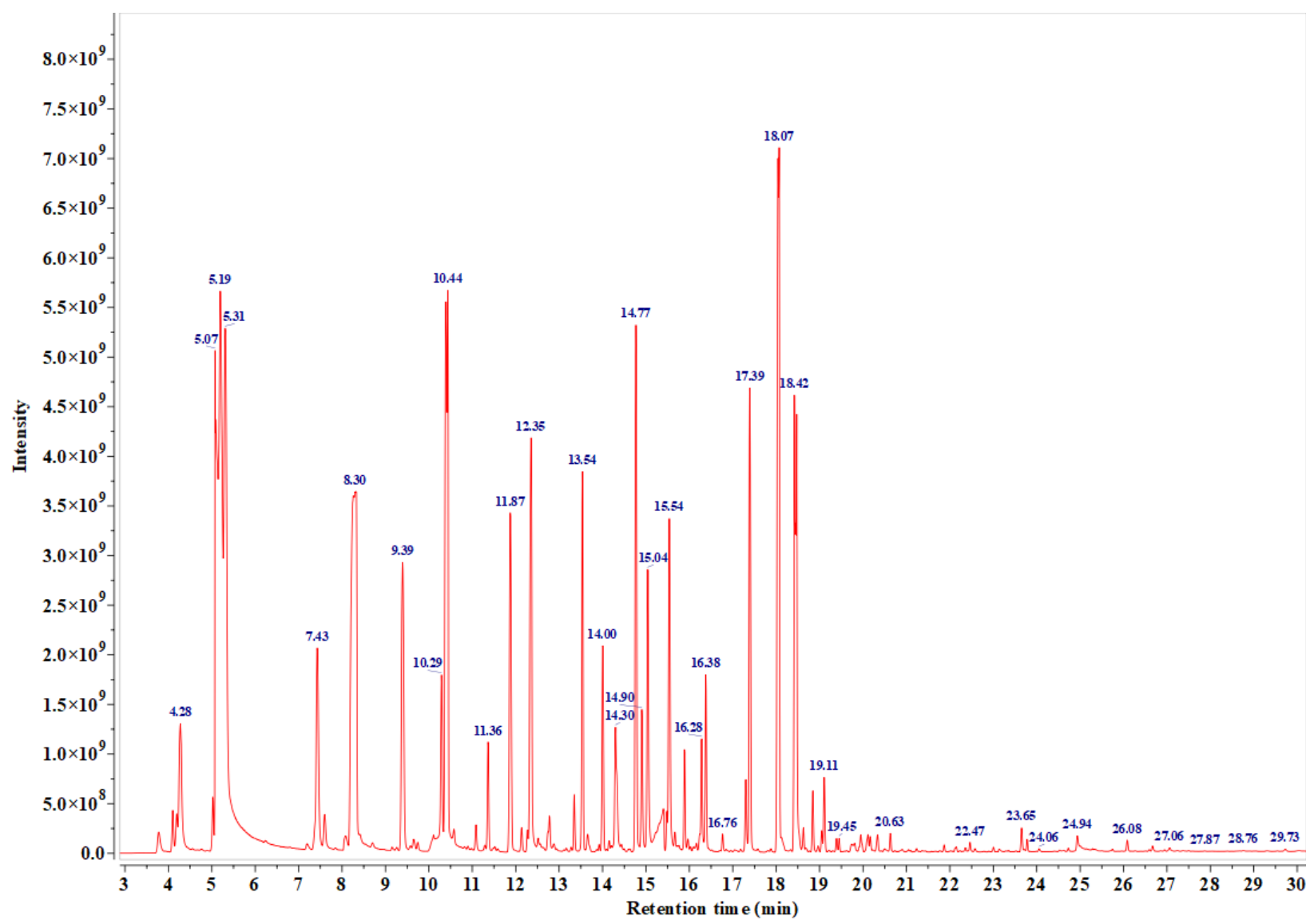

272 Figure S5. GC-MS total ion chromatogram of TD sampler after sampling AFFF headspace for 2 273 min after agitation 
275 High purity standards of three compounds were then injected into the same GC-MS/MS to

276 confirm fragmentation and retention time (Table S11). For 1H,1H,2H,2H-perfluorooctyl iodide

277 the spectra matched well between both of our injections and the TD-GC-MS (Figure S9B and

278 S9C), although the retention time varied slightly (4.2 min vs $4.98 \mathrm{~min}$ ), which likely arises

279 because this compound is poorly retained on our column, eluting near the void volume of the

280 column, and because the standard was injected in dichloromethane compared to the AFFF

281 headspace, injected as a gas (i.e., delay in vaporization of the solvent and analyte). A neat

282 standard of tridecafluoro-1-iodooct-1-ene was also poorly retained (4.15 min) but the spectrum

283 again matched well with TD-GC-MS spectrum (Figure S10A and S10B). Perfluorohexyl iodide

284 and (perfluorohexyl)ethylene were not detected by our instrument, likely because they were

285 eluted before the end of the filament delay, which agrees with the elution order observed for TD-

286 GC-MS. However, their mass spectrums and the spectrum for the fully fluorinated PFAS

287 (perfluorohexane) matched well with the NIST spectra. ${ }^{14}$

Table S11. List of putatively identified and confirmed PFASs from the TD sampler after sampling AFFF headspace for 2 min

\begin{tabular}{ccccc}
\hline $\begin{array}{c}\text { Retention } \\
\text { time (min) }\end{array}$ & PFAS & CAS No. & Supplier & Assay \\
\hline 4.102 & Perfluorohexane & $355-42-0$ & - & - \\
9.402 & (Perfluorohexyl)ethylene & $25291-17-2$ & Alfa Aesar & $99 \%$ \\
11.880 & Perfluorohexyl iodide & $355-43-1$ & Sigma Aldrich & $99 \%$ \\
17.301 & Tridecafluoro-1-iodooct-1-ene & $150223-14-6$ & Apollo scientific & $99 \%$ \\
18.419 & $1 \mathrm{H}, 1 \mathrm{H}, 2 \mathrm{H}, 2 \mathrm{H}-$ Perfluorooctyl iodide & $2043-57-4$ & Sigma Aldrich & $96 \%$ \\
8.102 & Unknown & NA & - & - \\
10.291 & Unknown & NA & - & - \\
14.904 & Unknown & NA & - & - \\
15.537 & Unknown & NA & - & - \\
\hline
\end{tabular}


Table S12. Proposed identification confidence criteria for the non-target compounds

\begin{tabular}{cccccc}
\hline PFAS & $\begin{array}{c}\text { Reference } \\
\text { Standard }\end{array}$ & $\begin{array}{c}\text { Direct Injection of } \\
\text { AFFF Headspace }\end{array}$ & $\begin{array}{c}\text { NIST Library } \\
\text { Reference }\end{array}$ & $\begin{array}{c}\text { Retention } \\
\text { Time }\end{array}$ & $\begin{array}{c}\text { Identification } \\
\text { Confidence III }\end{array}$ \\
\hline $\begin{array}{c}\text { Perfluorohexane } \\
\text { (Perfluorohexyl)ethylene }\end{array}$ & $\mathrm{NA}^{\mathrm{I}}$ & $\mathrm{NA}$ & Match & NA & Level 3 \\
$\begin{array}{c}\text { Perfluorohexyl iodide } \\
\text { Tridecafluoro-1-iodooct- } \\
\begin{array}{c}\text { 1-ene } \\
\text { 1H,1H,2H,2H- }\end{array}\end{array}$ & NM & NA & Match & NM & Level 3 \\
Merfluorooctyl iodide & Match & Match & Match & NM & Level 3 \\
\hline
\end{tabular}

I. NA: not available

II. NM: not matched

III. The matching criteria were demonstrated in section 3.3 in the main text

IV. Level of identification confidence were reported by Schymanski et al, ${ }^{15}$ Level 1:

Confirmed structure; Level 2a: Probable structure by library spectrum match; Level 2b: Probable structure by diagnostic evidence; Level 3: Tentative candidate(s); Level 4: Unequivocal molecular formula; Level 5: Exact mass of interest.

Perfluorohexane, (perfluorohexyl)ethylene and perfluorohexyl iodide were only confirmed by matching fragmentation spectrums with NIST library. Normally, this should be sufficient to increase the level of confidence to "probable structure", however, since NIST library do not include all the different acquisition parameters to compare to ours, we decided to report these compounds with level 3 confidence "Tentative candidates". Additionally, $1 \mathrm{H}, 1 \mathrm{H}, 2 \mathrm{H}, 2 \mathrm{H}-$ Perfluorooctyl iodide was scored at level 3 due to absence of any confirmation other than a match in the MS fragmentation spectra with a standard reference. Only tridecafluoro-1-iodooct1-ene scored as probable structure with diagnostic evidence "level 2b" due to the confirmations with three matches including mass spectrum with standard reference, retention time and experimental data by direct injection of AFFF headspace. 


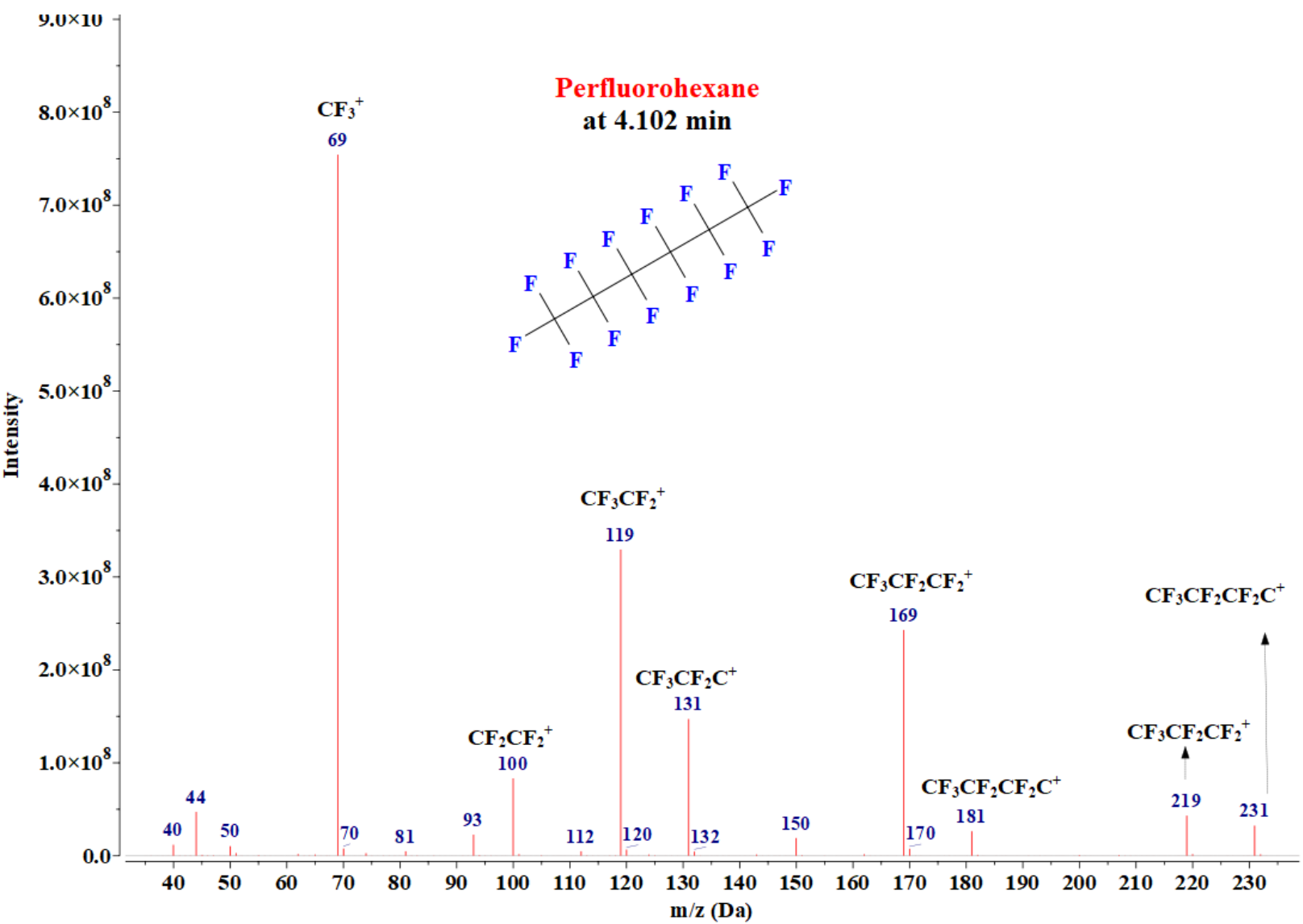

313 Figure S6. Mass spectrum for the tentatively identified perfluorohexane found in the 2 min TD 


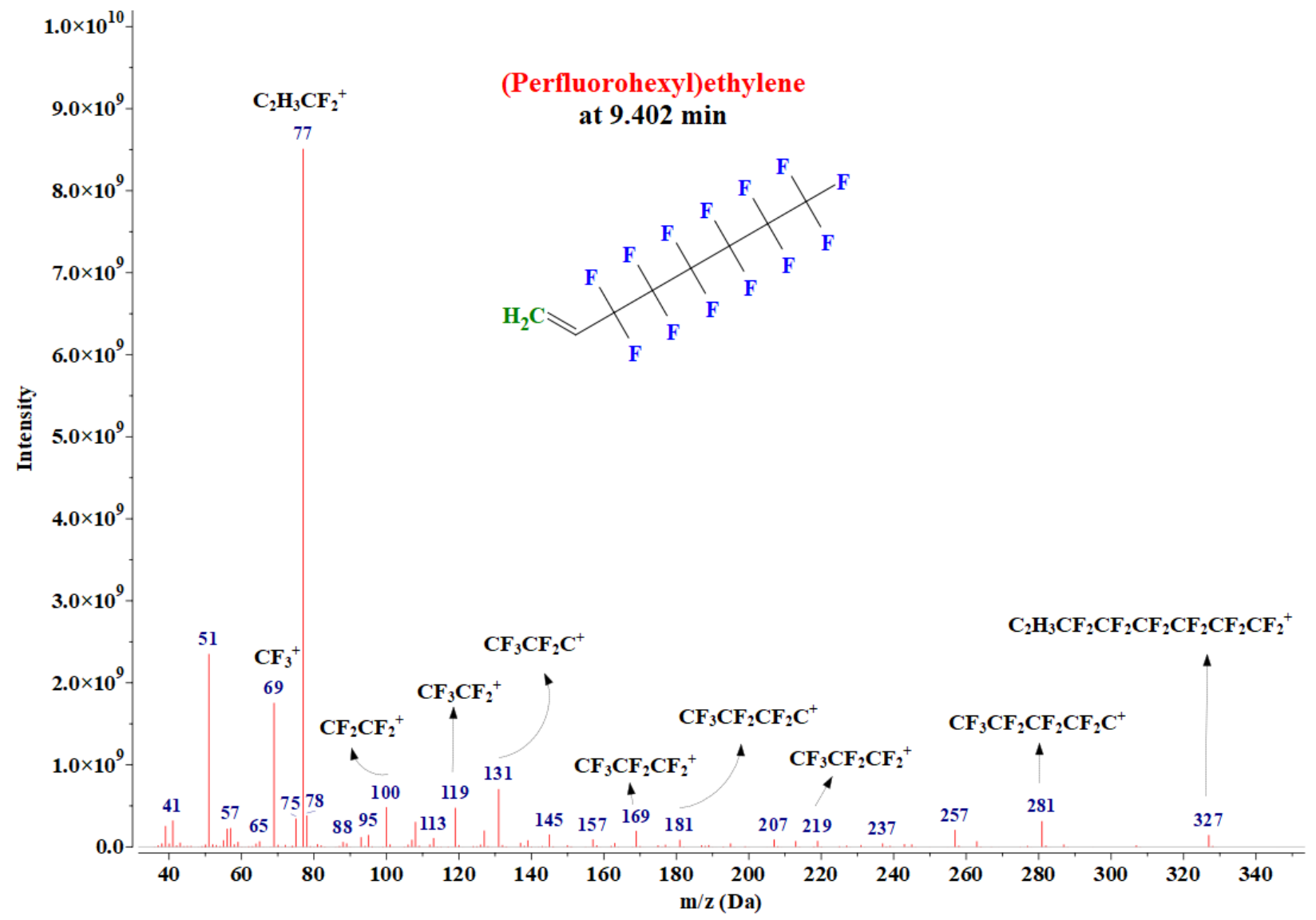

317 Figure S7. Mass spectrum for the tentatively identified (Perfluorohexyl)ethylene found in 2 min 318 TD sampler analyzed by GC-MS 


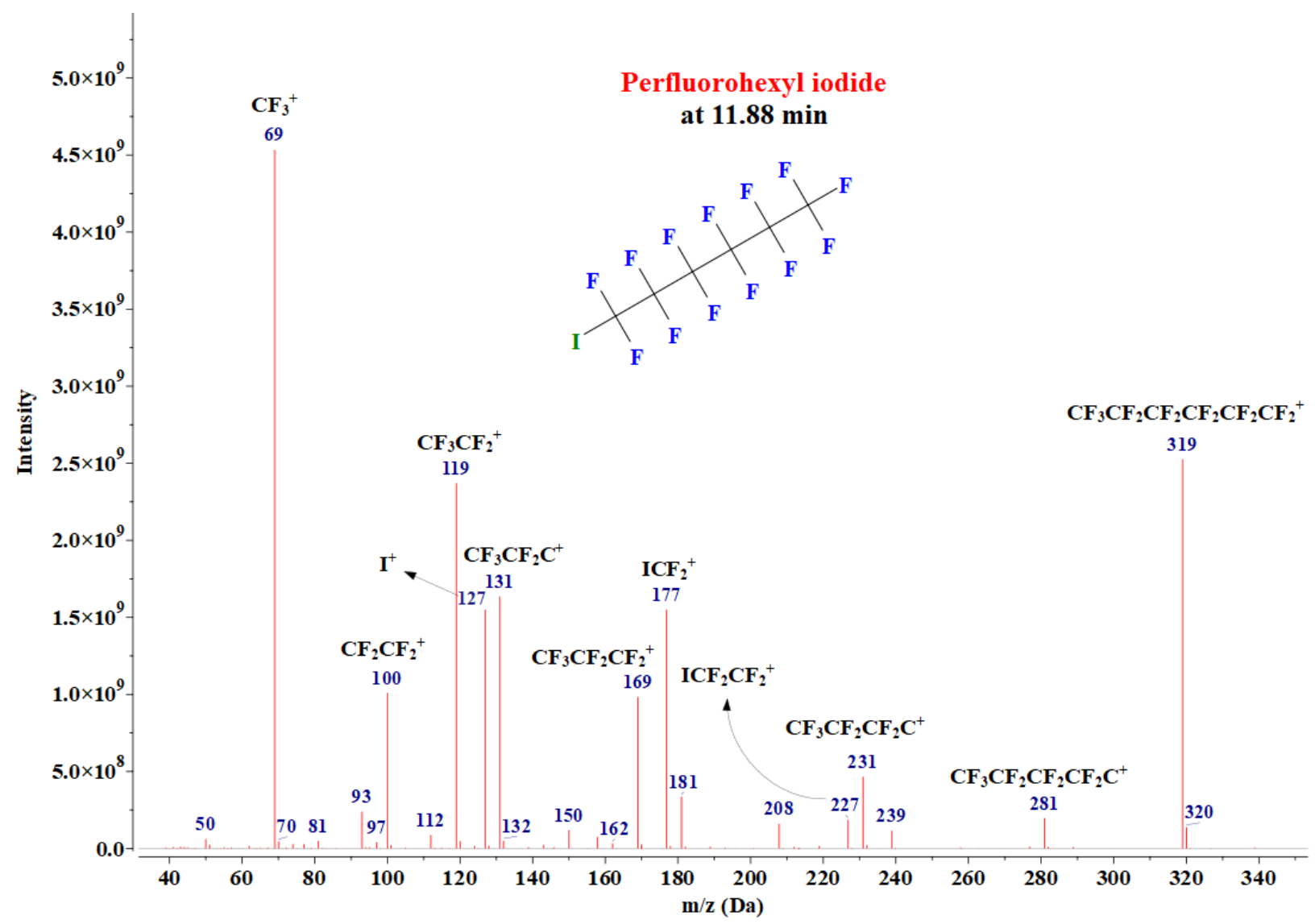

321 Figure S8. Mass spectrum for the tentatively identified perfluorohexyl iodide found in the 2 min TD sampler analyzed by GC-MS 


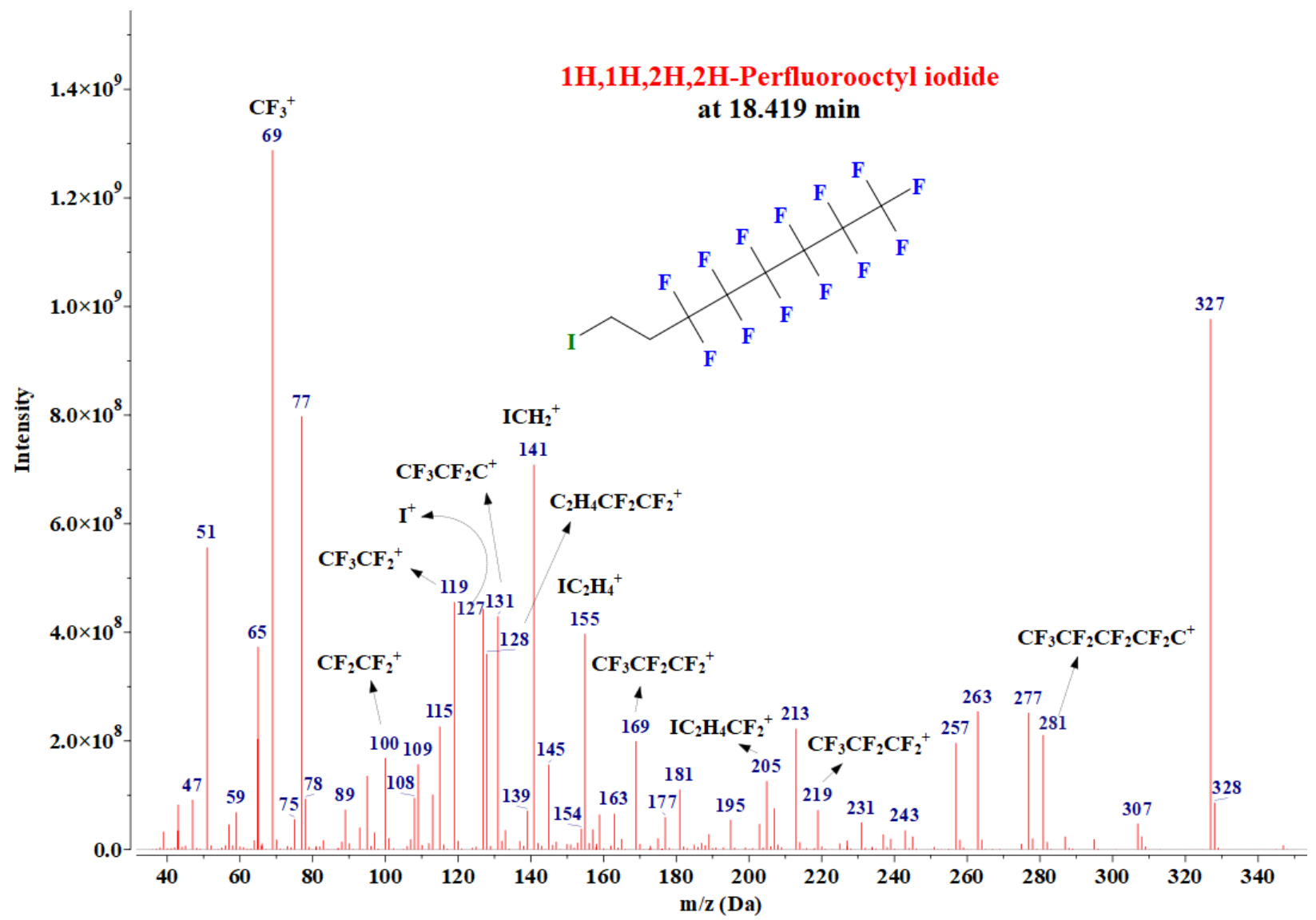

327 Figure S9A. Mass spectrum for the tentatively identified $1 \mathrm{H}, 1 \mathrm{H}, 2 \mathrm{H}, 2 \mathrm{H}$-Perfluorooctyl iodide found in the 2 min TD sampler analyzed by GC-MS 


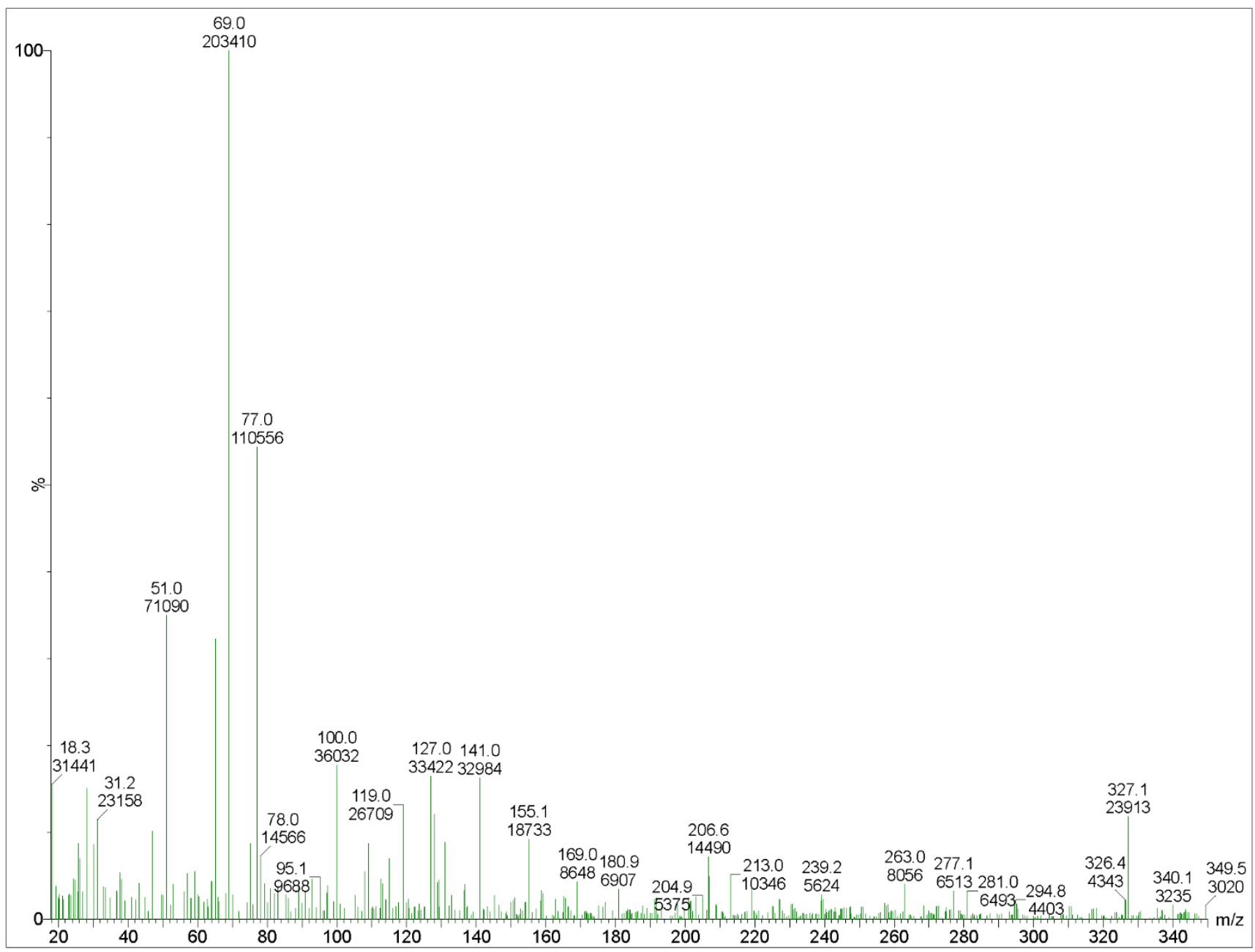

341 Figure S9B. Mass spectrum of $1 \mathrm{H}, 1 \mathrm{H}, 2 \mathrm{H}, 2 \mathrm{H}$-Perfluorooctyl iodide standard in dichloromethane 342 at $4.98 \mathrm{~min}$ analyzed by GC-MS 


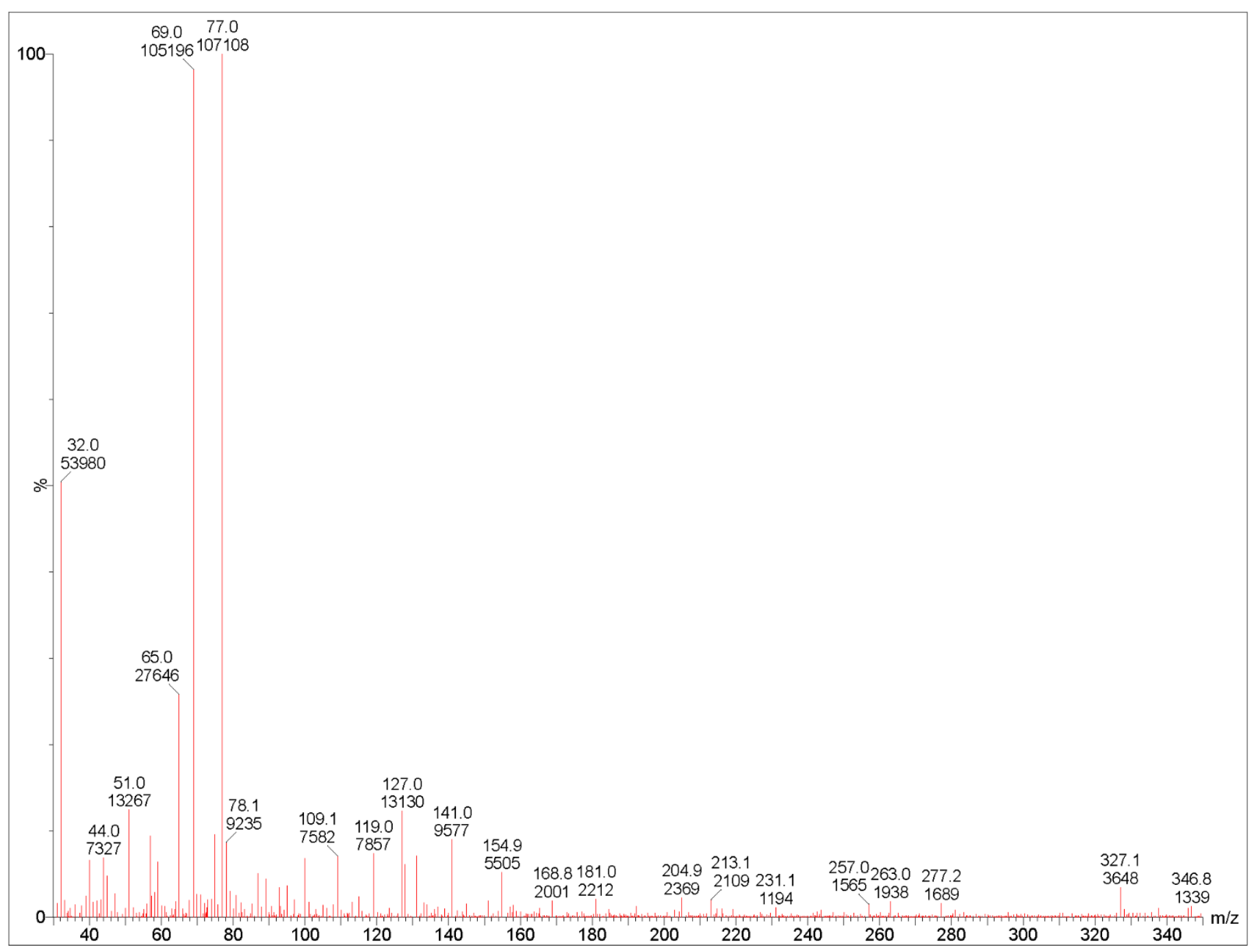

351 Figure S9C. Mass spectrum of $1 \mathrm{H}, 1 \mathrm{H}, 2 \mathrm{H}, 2 \mathrm{H}$-Perfluorooctyl iodide in AFFF headspace at 4.20 min analyzed by GC-MS 


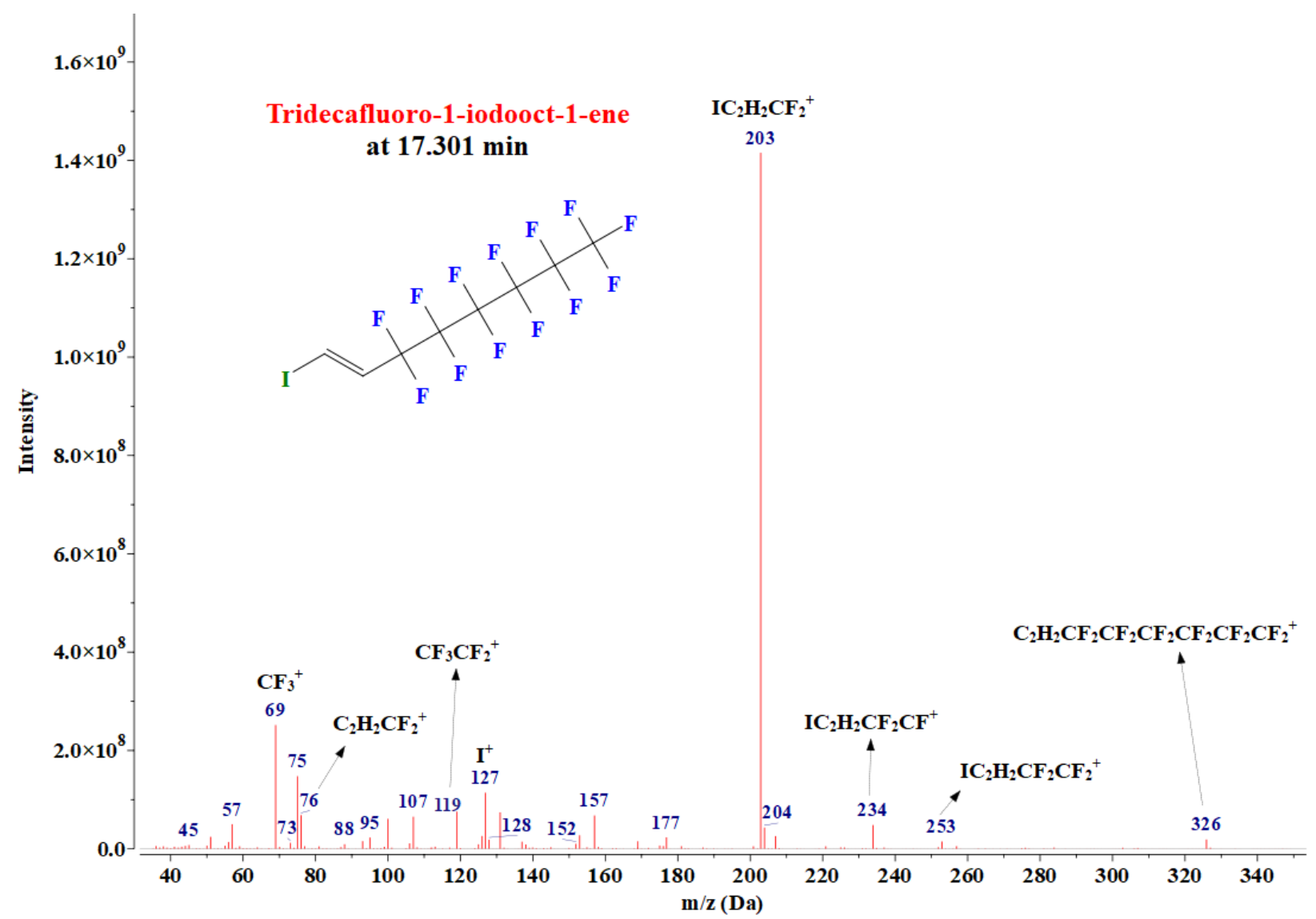

Figure S10A. Mass spectrum for the tentatively identified tridecafluoro-1-iodooct-1-ene found in the 2 min TD sampler analyzed by GC-MS 


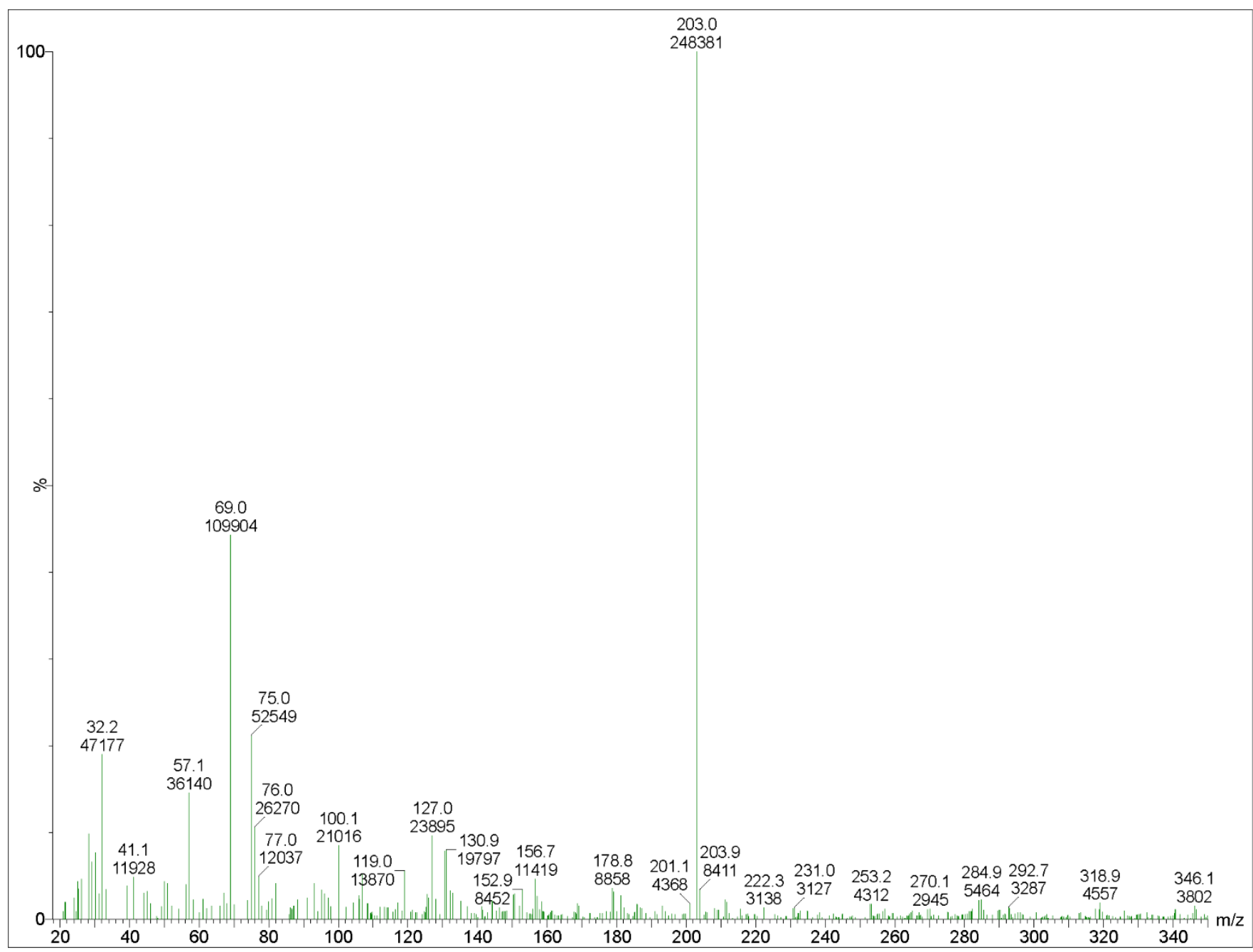

364 Figure S10B. Mass spectrum for tridecafluoro-1-iodooct-1-ene standard in dichloromethane at 365 4.15 min analyzed by GC-MS

366

367 


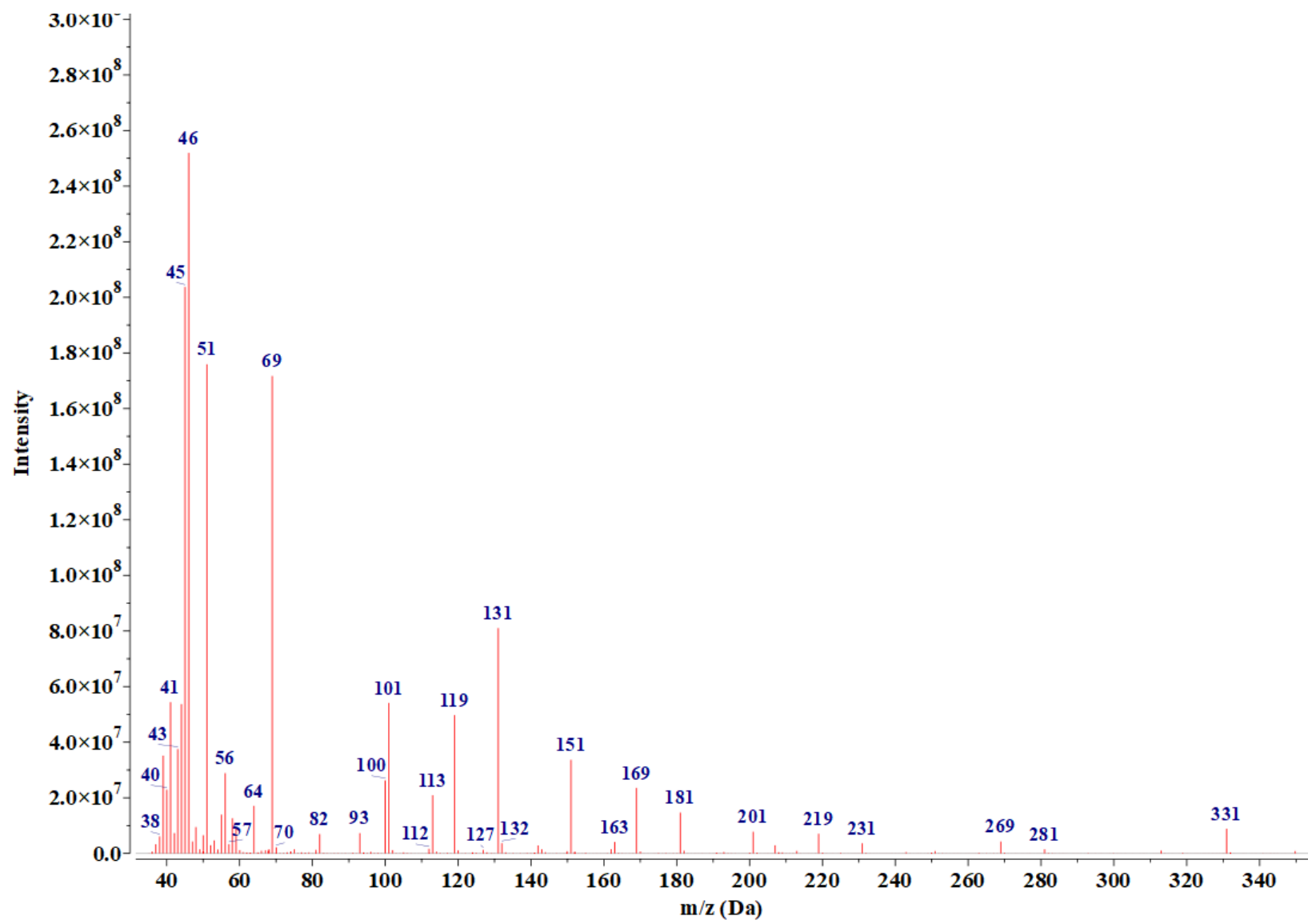

Figure S11. Mass spectrum for unidentified PFAS at 8.102 min found in the 2 min TD sampler analyzed by GC-MS 


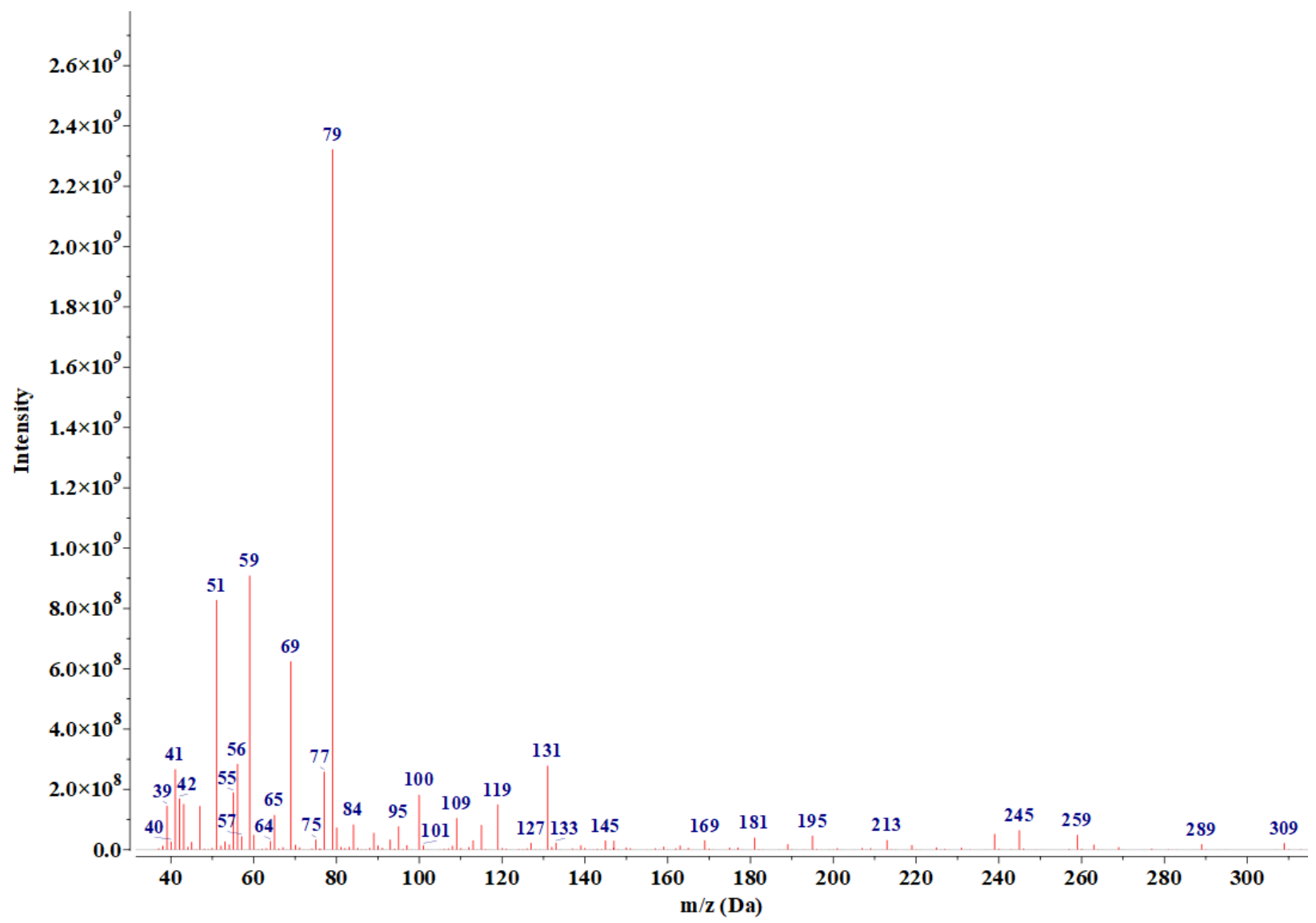

372 Figure S12. Mass spectrum for unidentified PFAS at $10.291 \mathrm{~min}$ found in the 2 min TD sampler 373 analyzed by GC-MS

374 


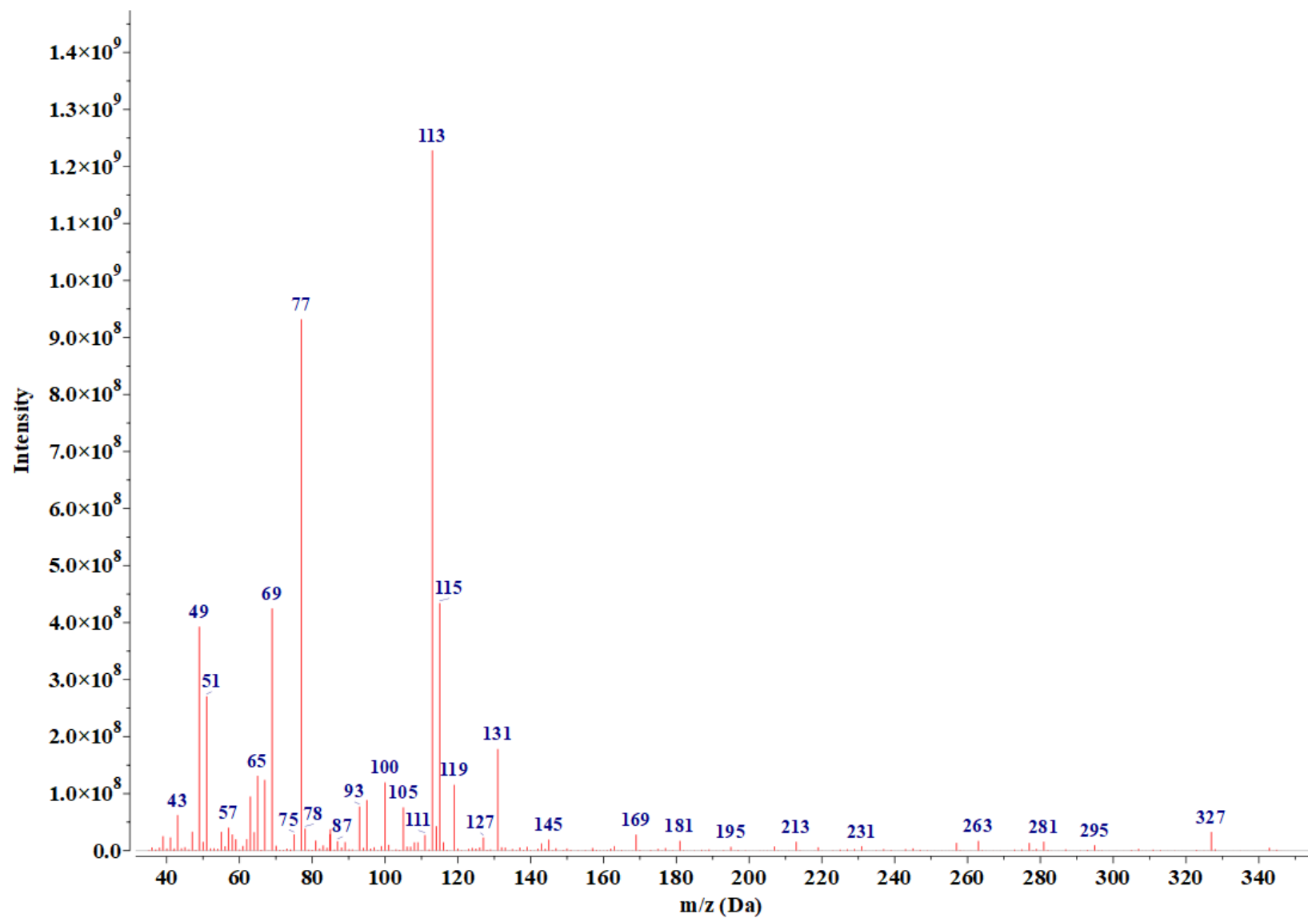

375 Figure S13. Mass spectrum for unidentified PFAS at 14.904 min found in the 2 min TD sampler 376 analyzed by GC-MS

377

378 


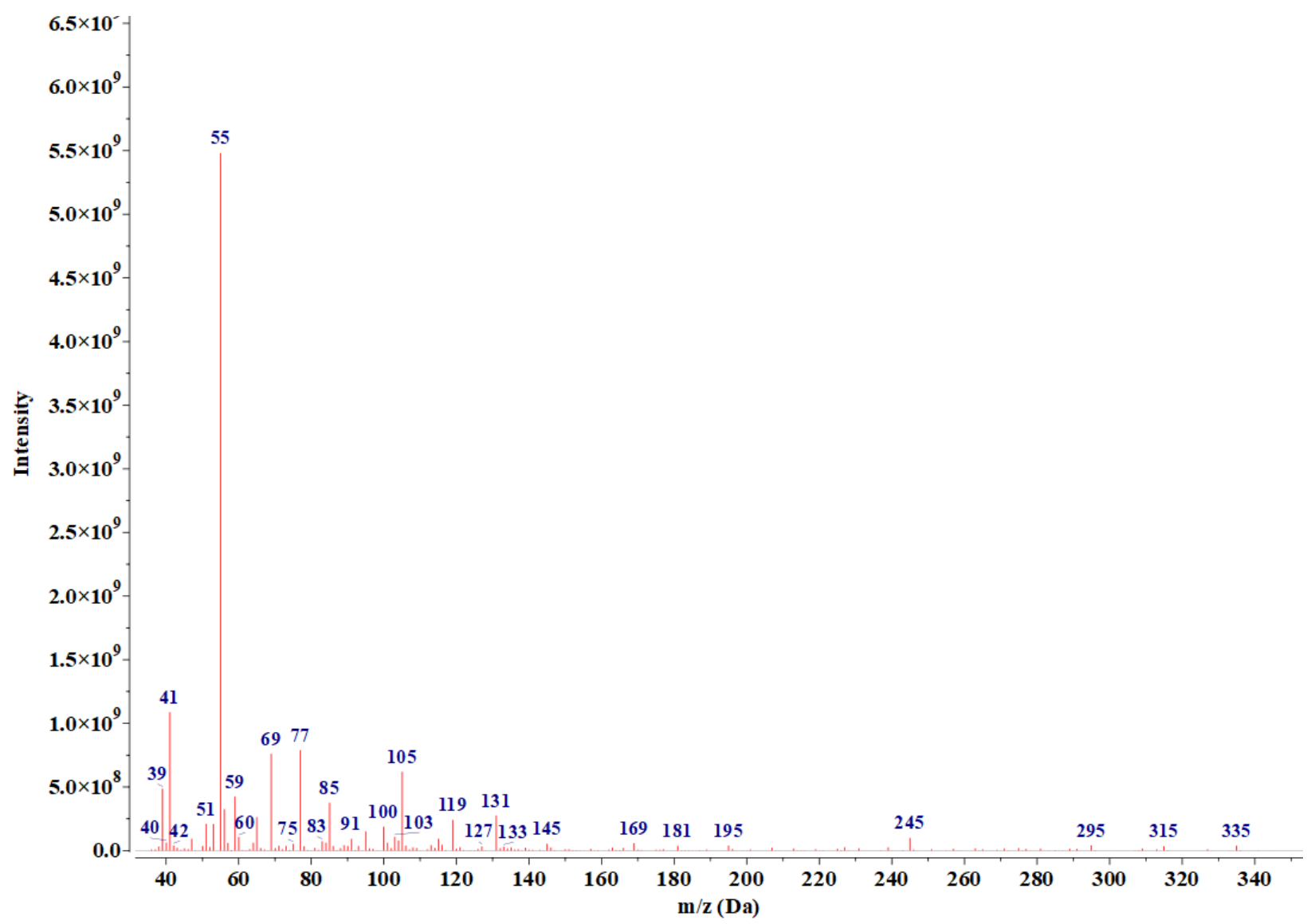

Figure S14. Mass spectrum for unidentified PFAS at $15.537 \mathrm{~min}$ found in the 2 min TD sampler 380 analyzed by GC-MS

381 

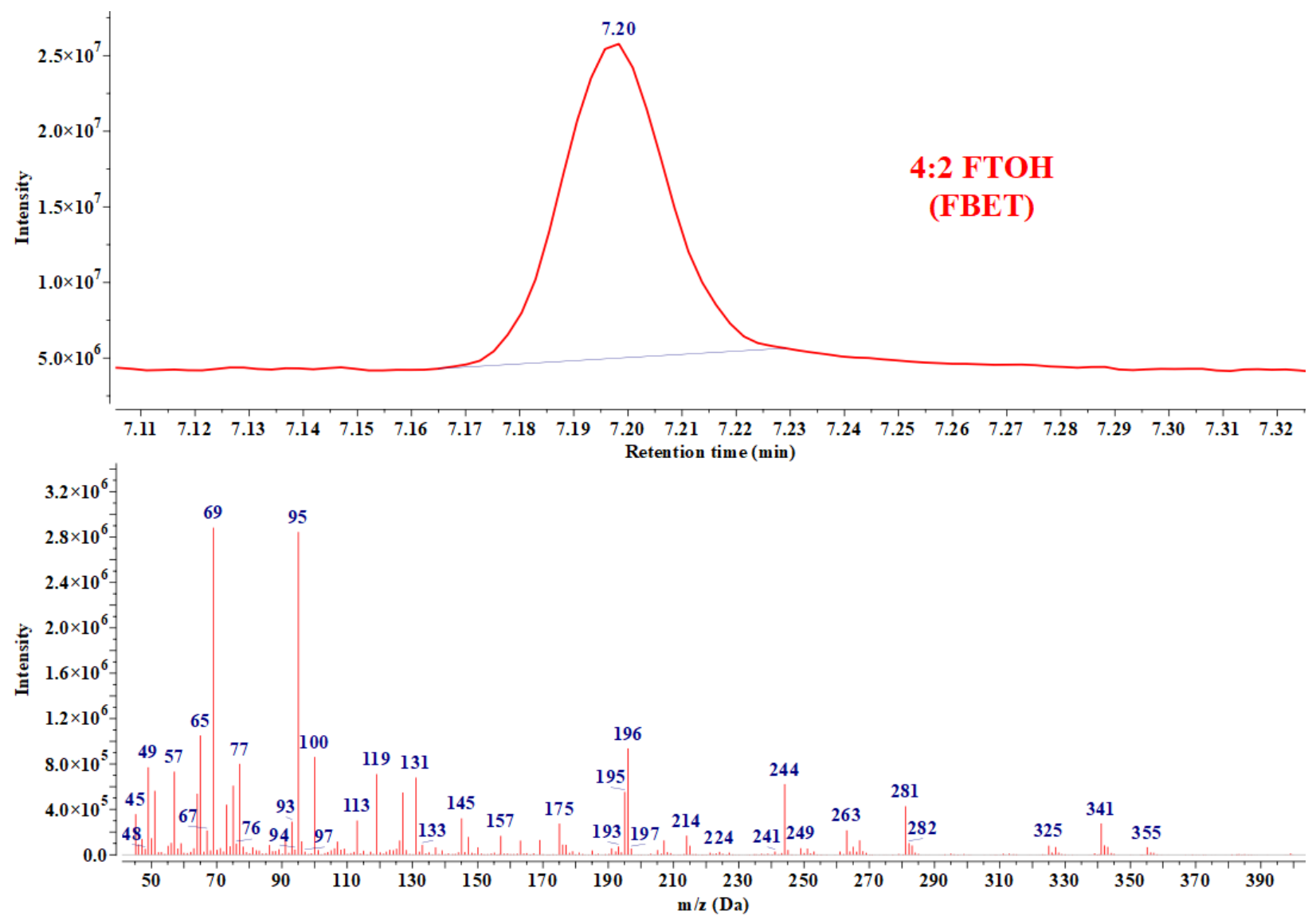

396 Figure S15. Mass spectrum and retention time for 4:2 FTOH standard injected into GC-MS 

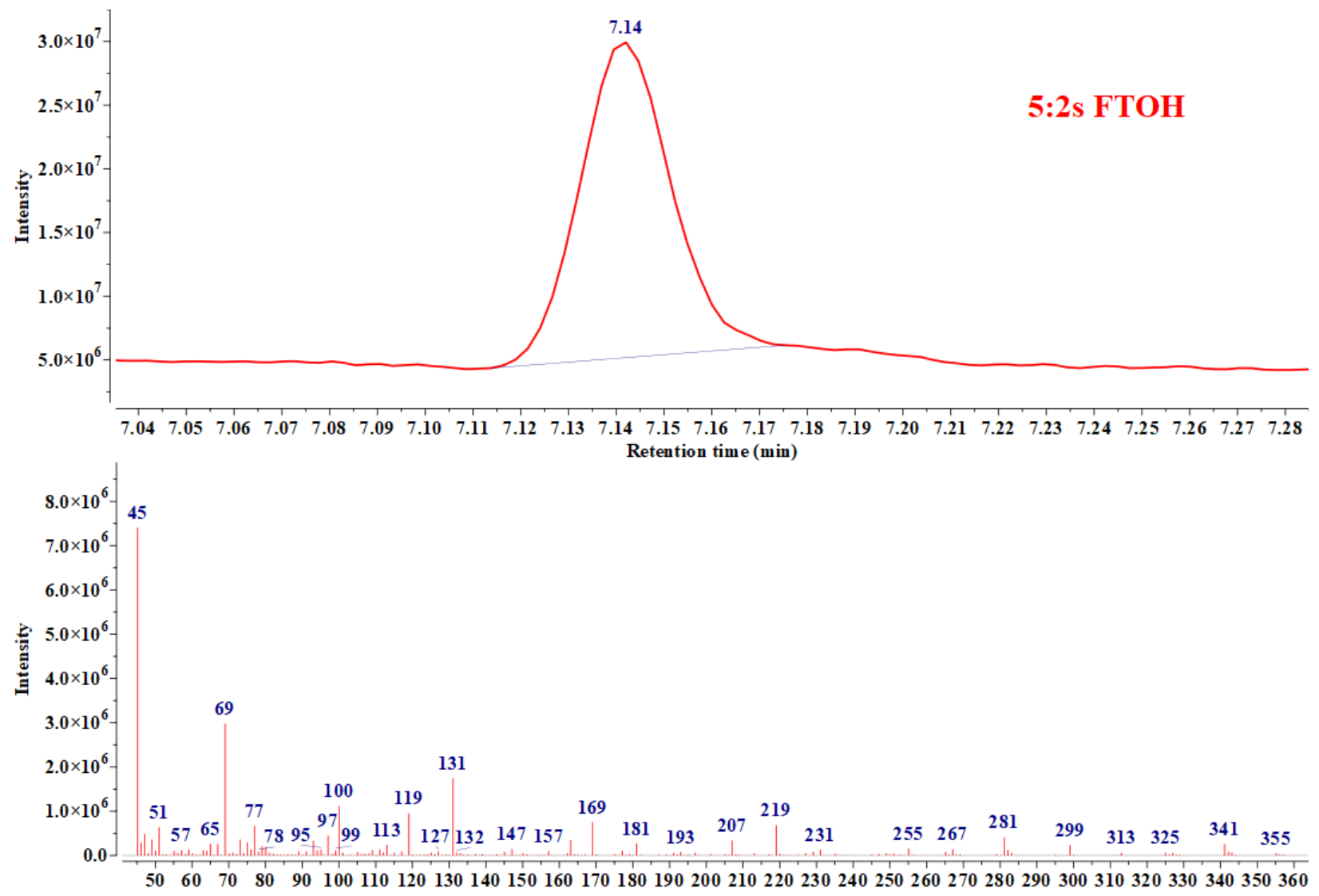
$\mathbf{m} / \mathbf{z}(\mathbf{D a})$

Figure S16. Mass spectrum and retention time for 5:2s FTOH standard injected into GC-MS 

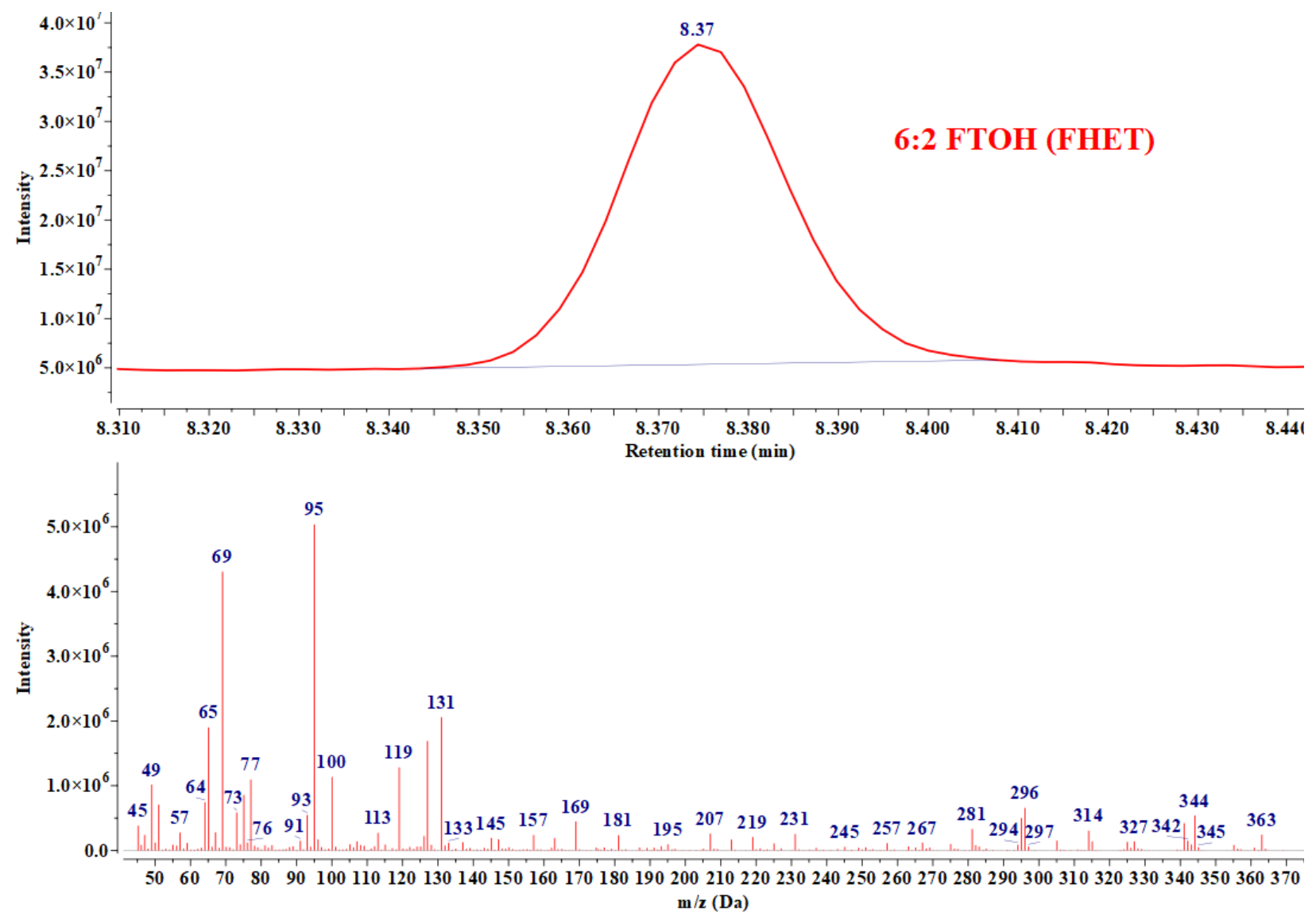

423 Figure S17. Mass spectrum and retention time for 6:2 FTOH standard injected into GC-MS

424

425

426

427

428

429

430

431

432

433 

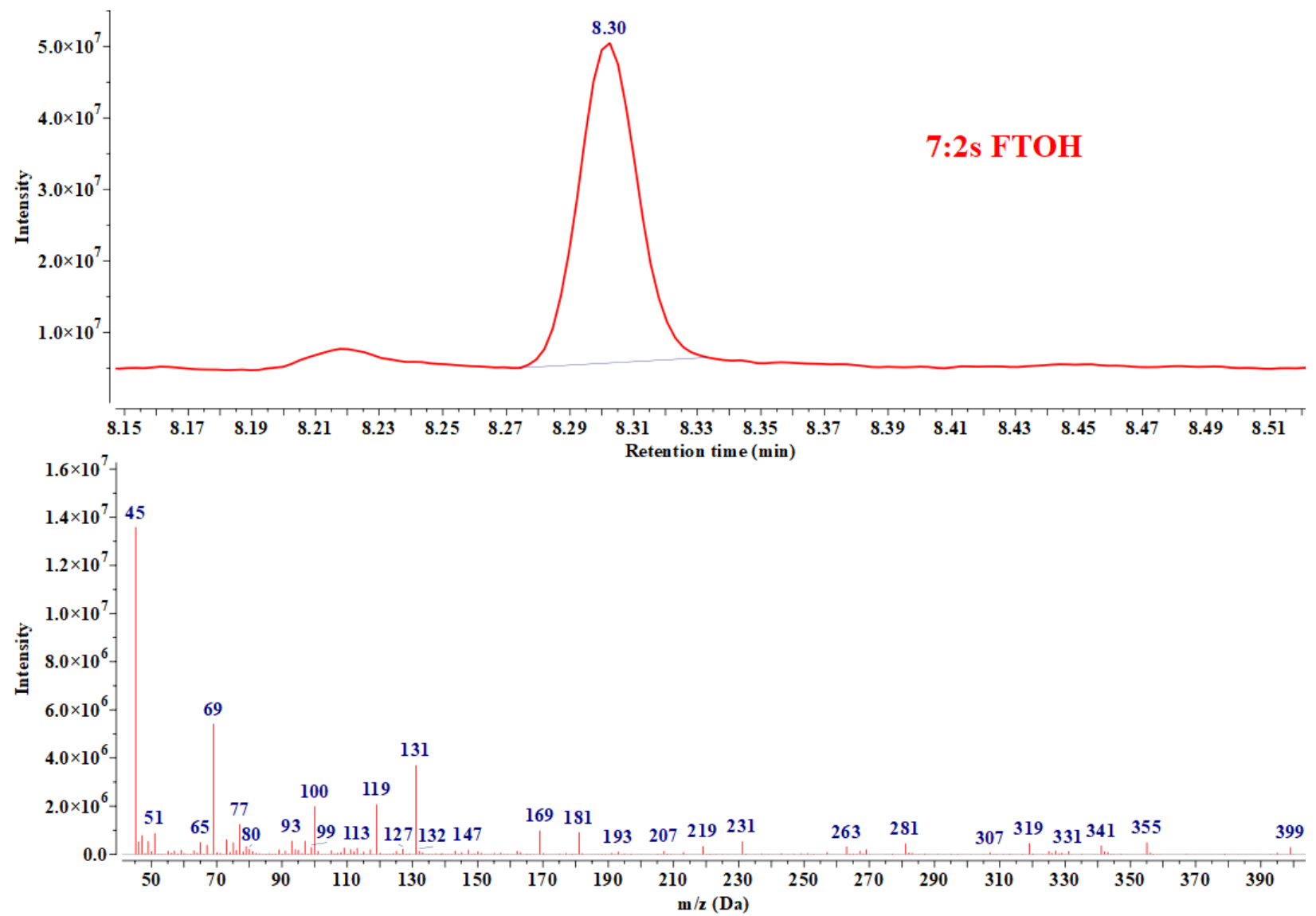

437 Figure S18. Mass spectrum and retention time for 7:2s FTOH standard injected into GC-MS 

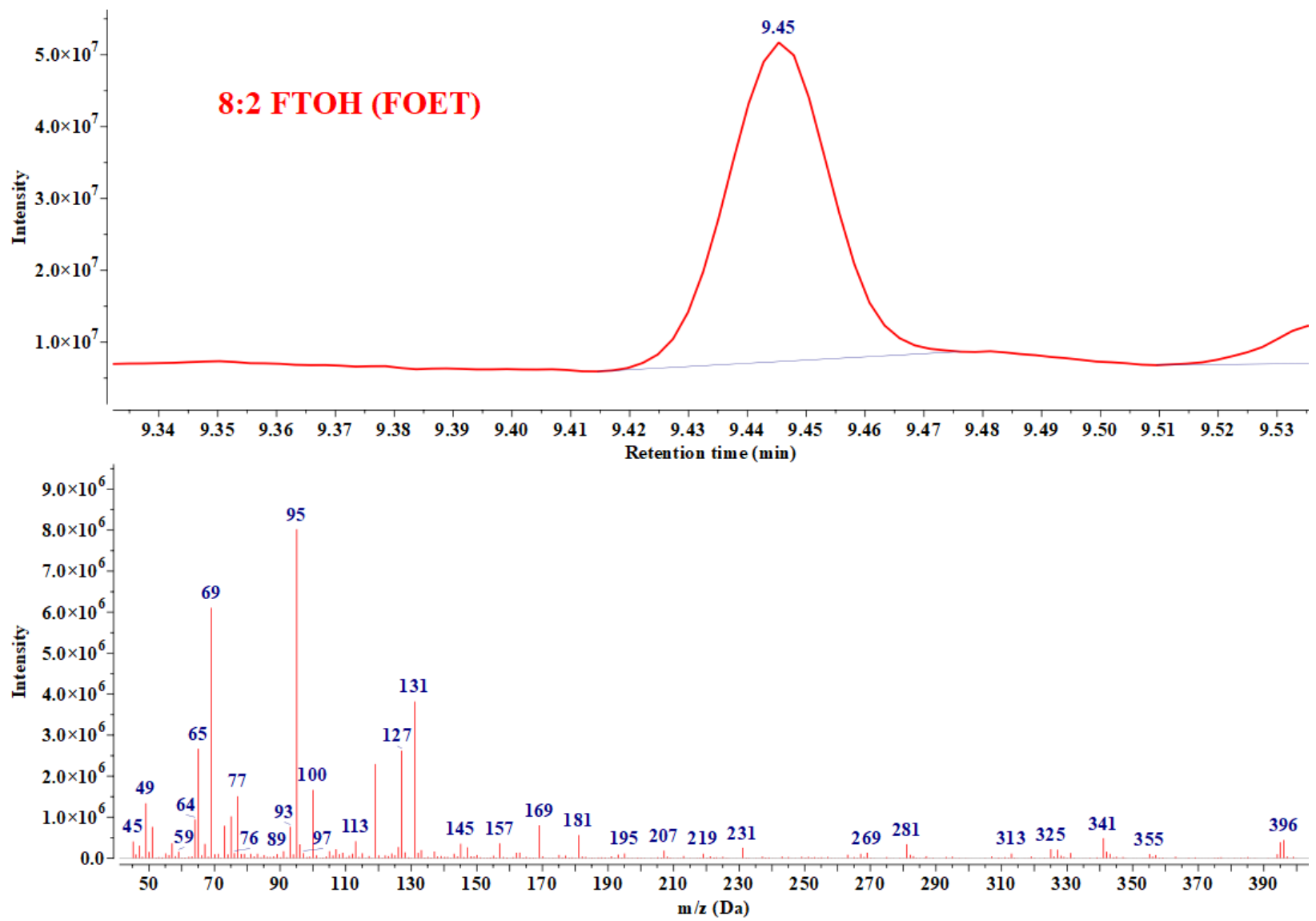

Figure S19. Mass spectrum and retention time for 8:2 FTOH standard injected into GC-MS

451 

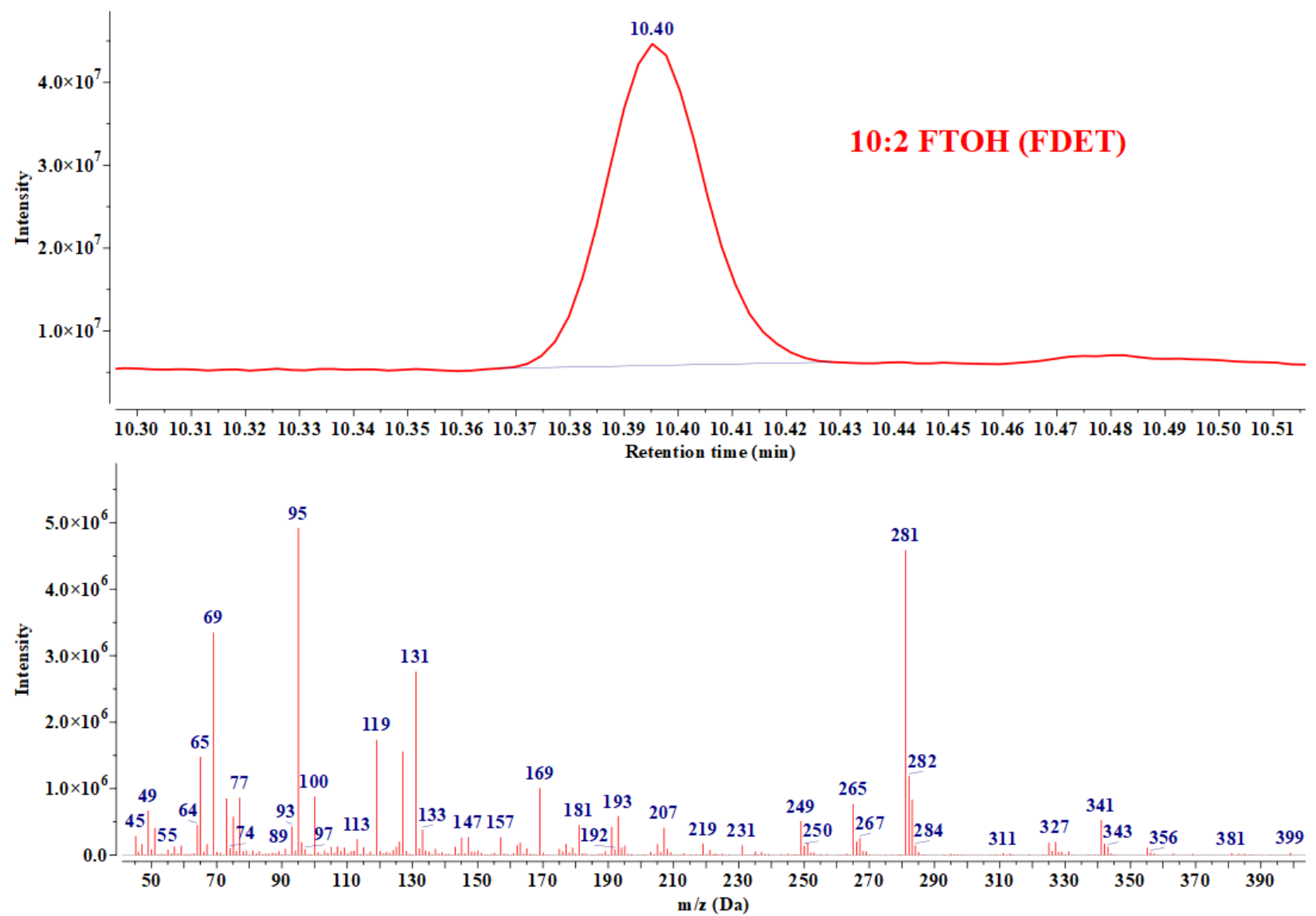

464 Figure S20. Mass spectrum and retention time for 10:2 FTOH standard injected into GC-MS 

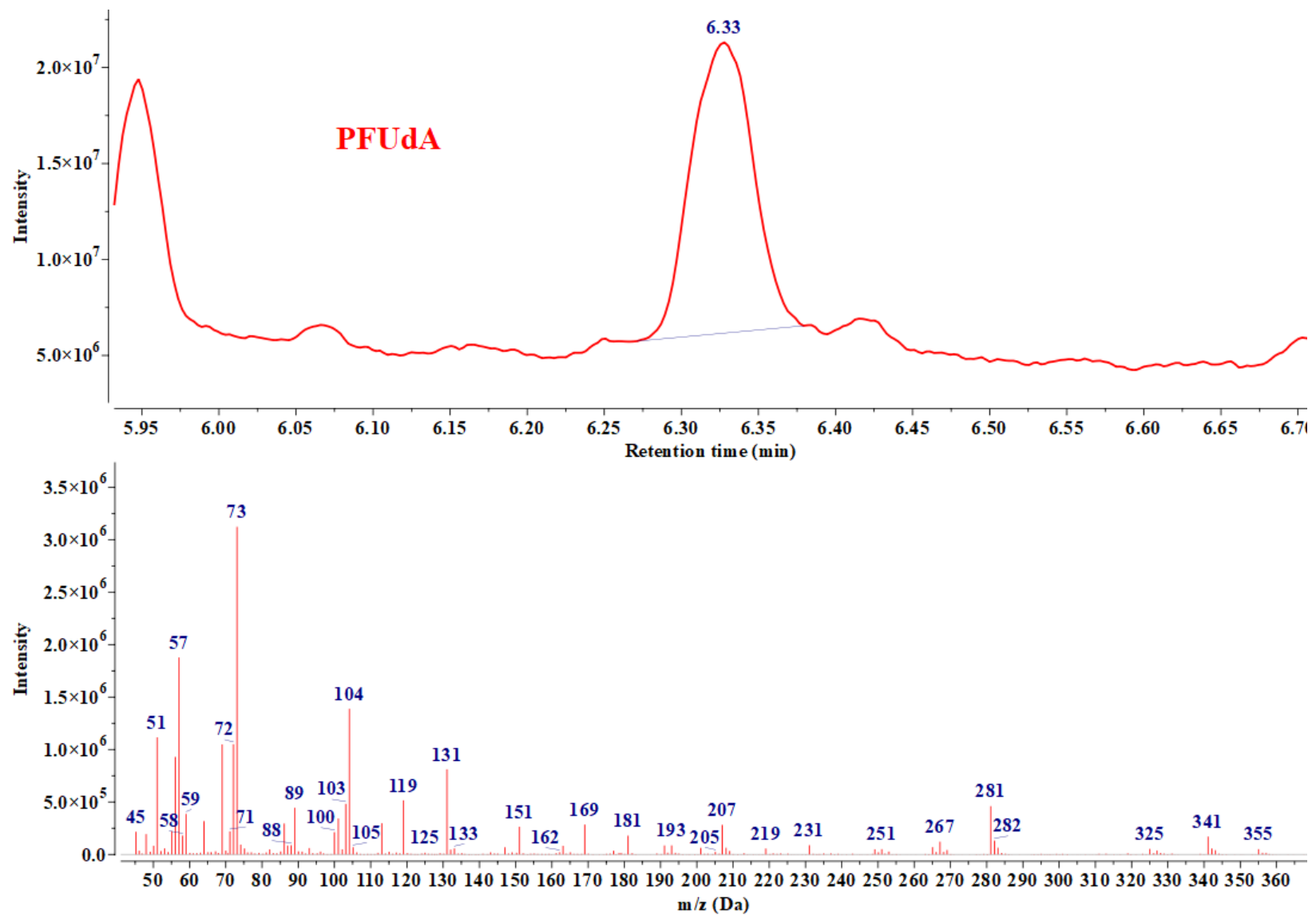

Figure S21. Mass spectrum and retention time for PFUdA standard injected into GC-MS 

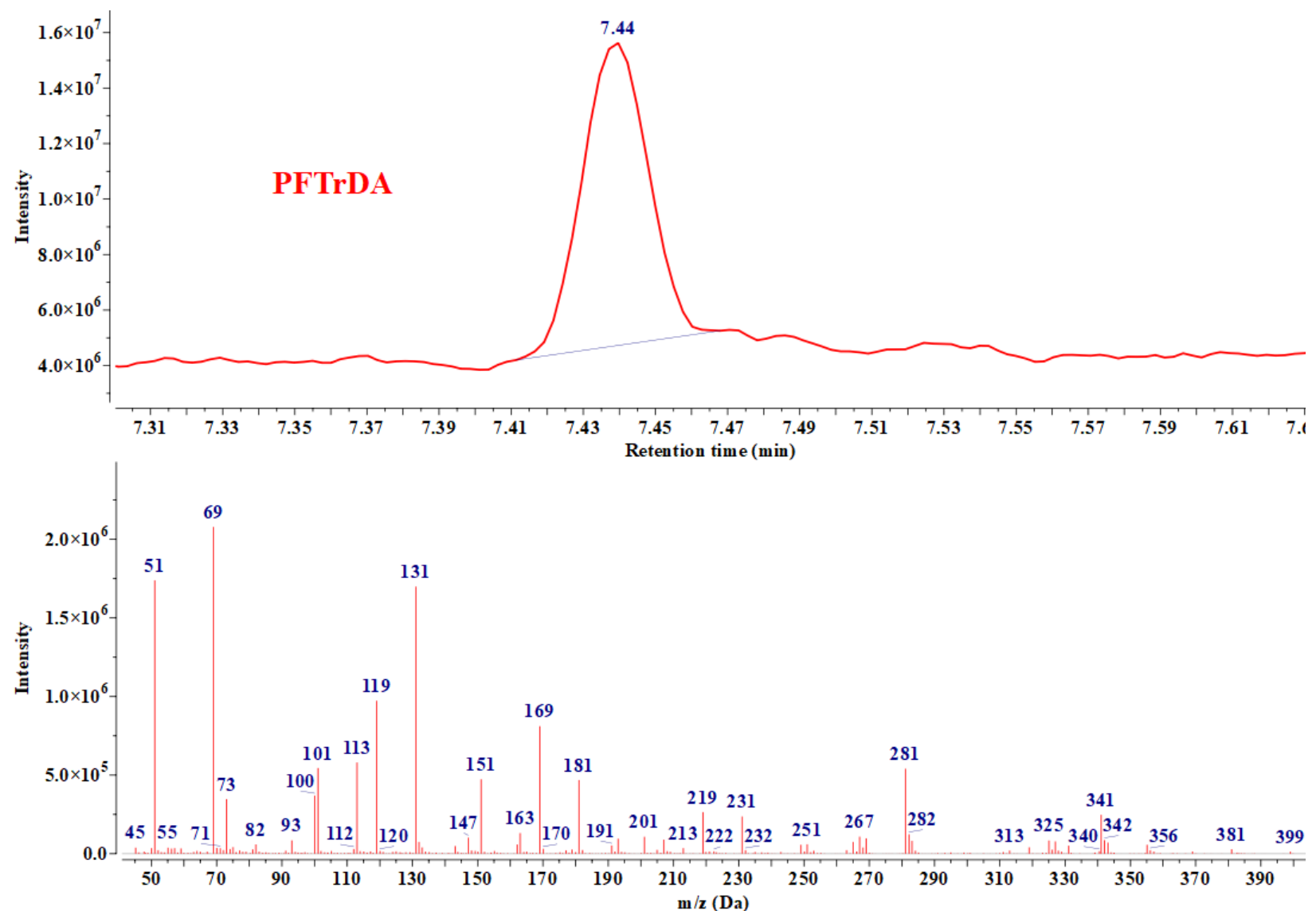

492 Figure S22. Mass spectrum and retention time for PFTrDA standard injected into GC-MS 
505
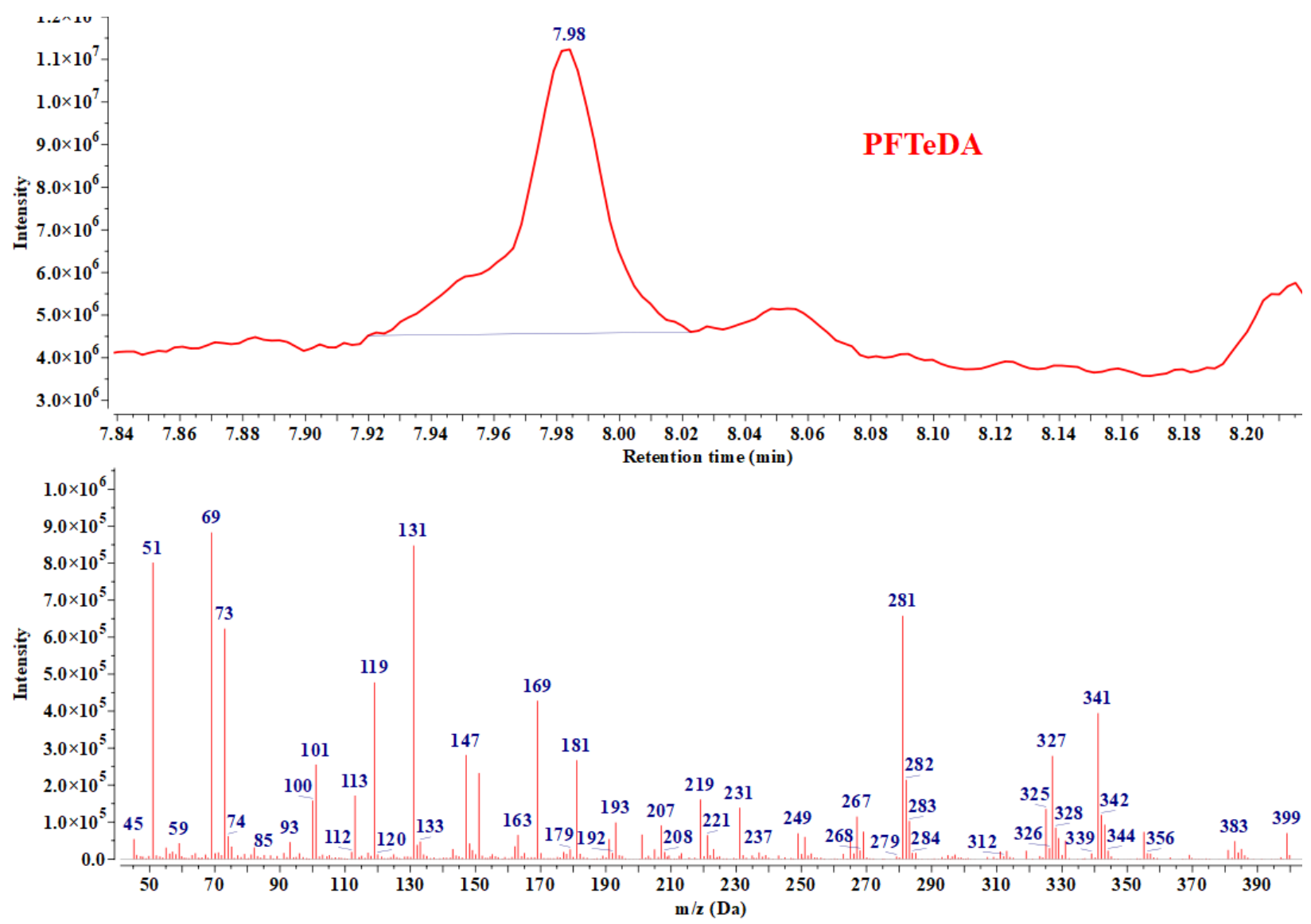

506 Figure S23. Mass spectrum and retention time for PFTeDA standard injected into GC-MS 

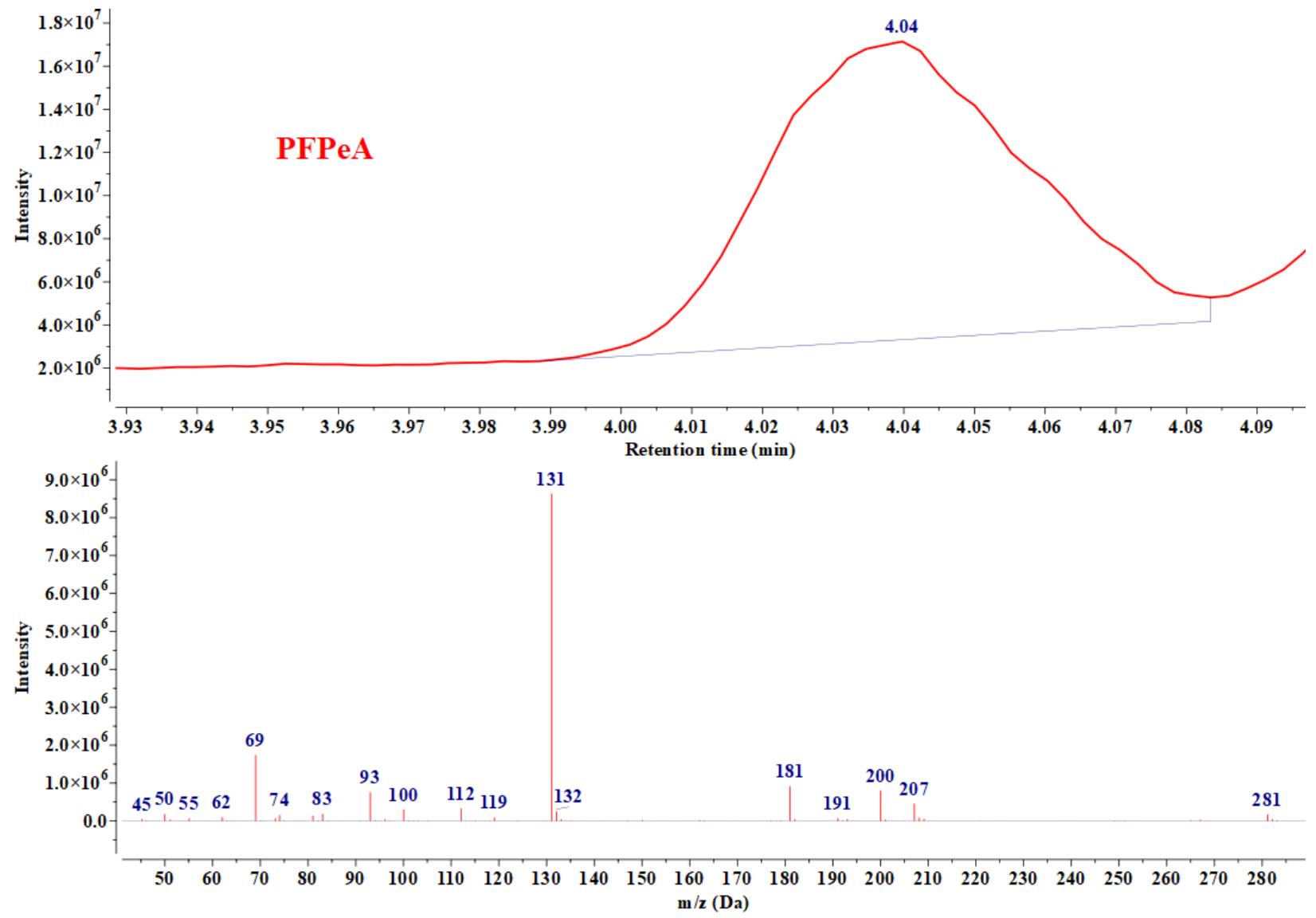

Figure S24. Mass spectrum and retention time for PFPeA standard injected into GC-MS 

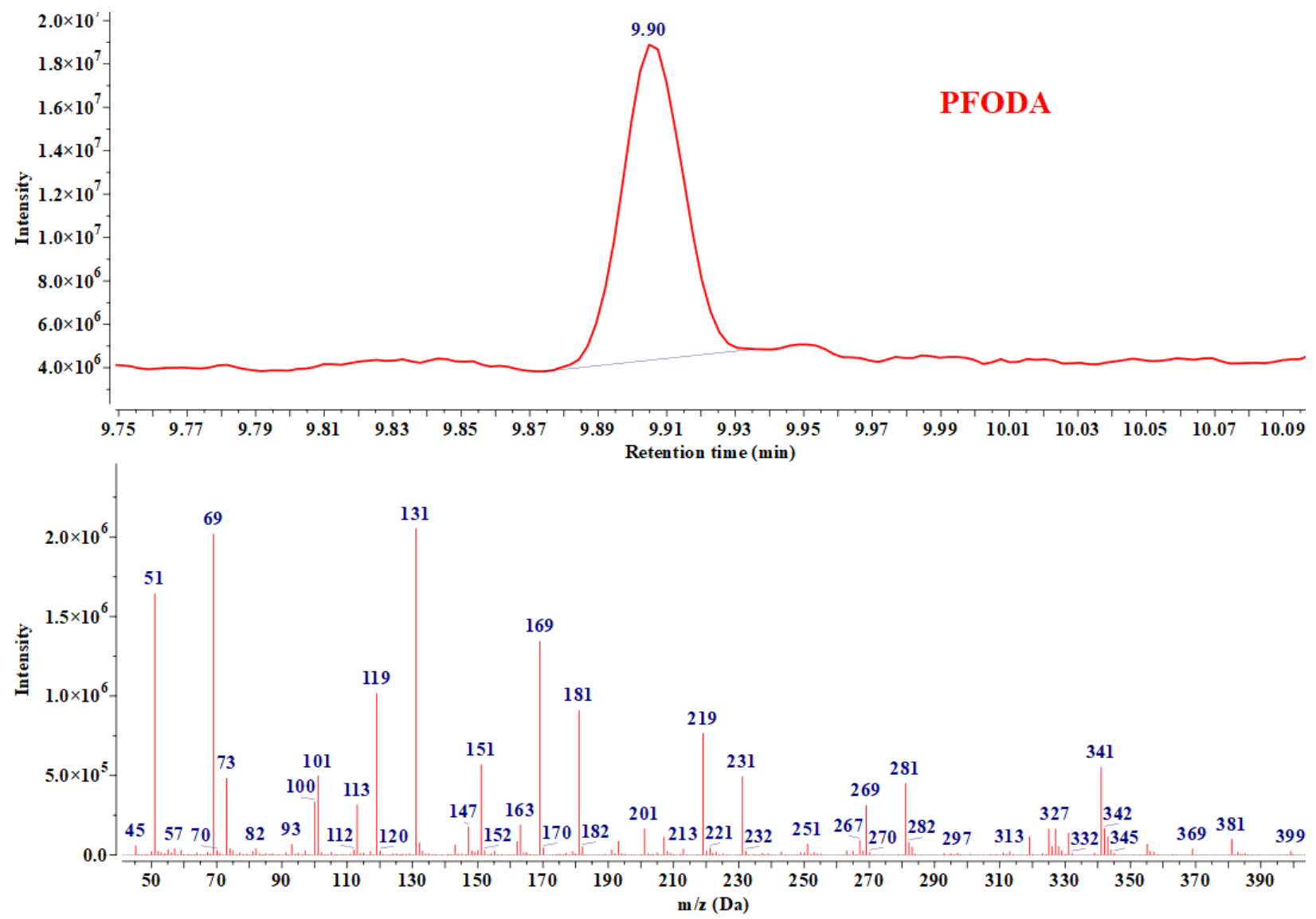

534 Figure S25. Mass spectrum and retention time for PFODA standard injected into GC-MS 

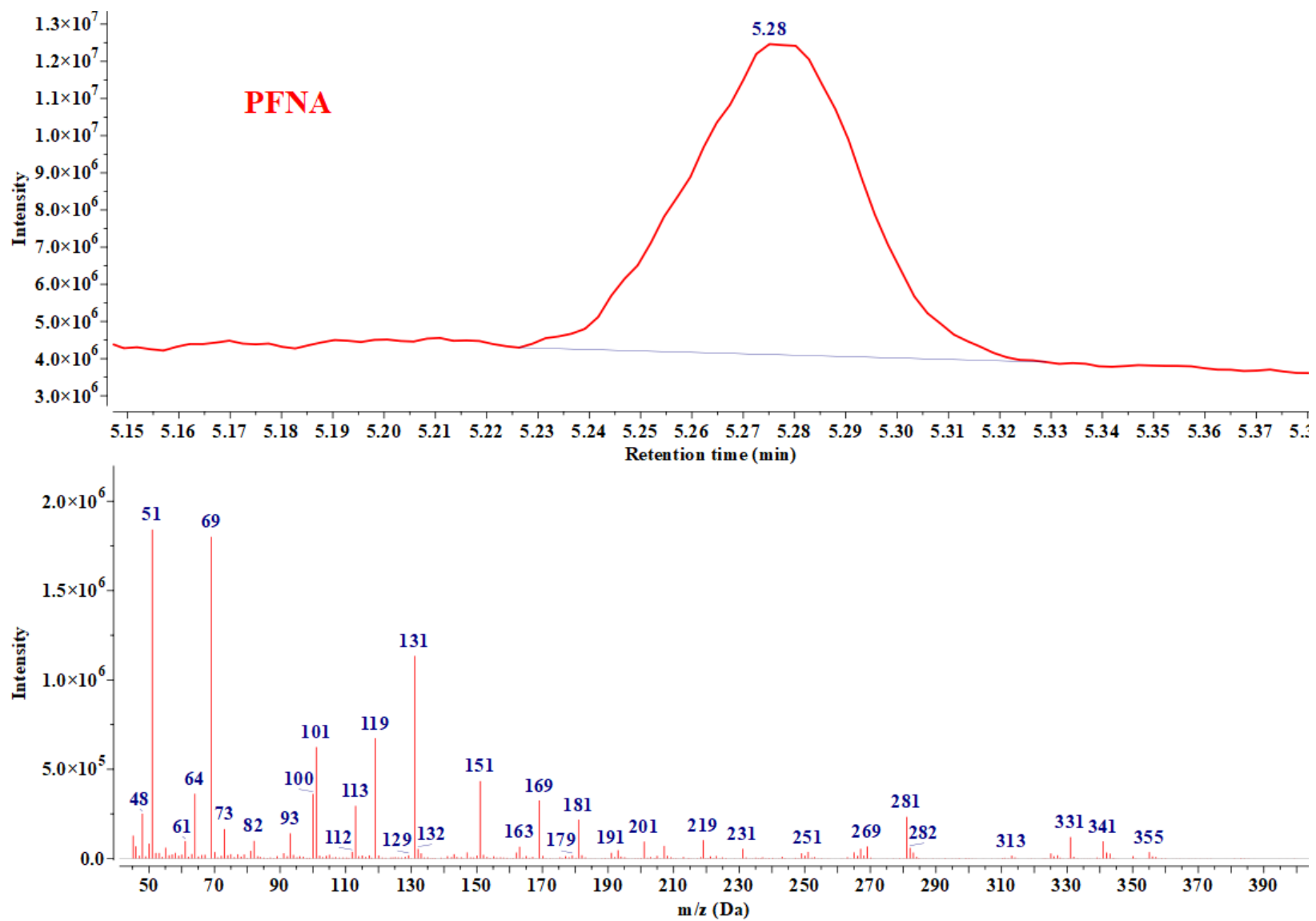

$548 \quad$ Figure S26. Mass spectrum and retention time for PFNA standard injected into GC-MS 
561
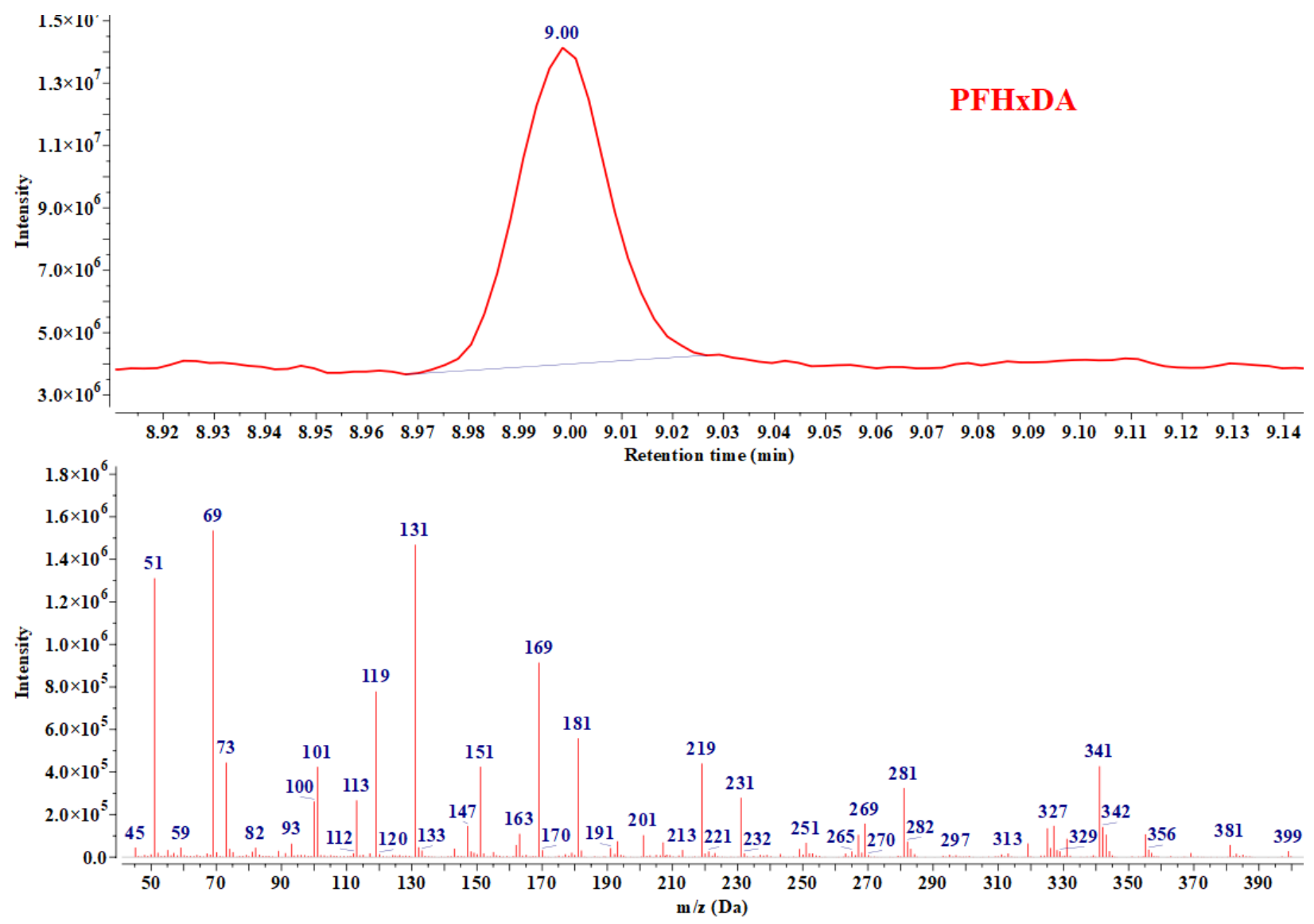

562 Figure S27. Mass spectrum and retention time for PFHxDA standard injected into GC-MS 

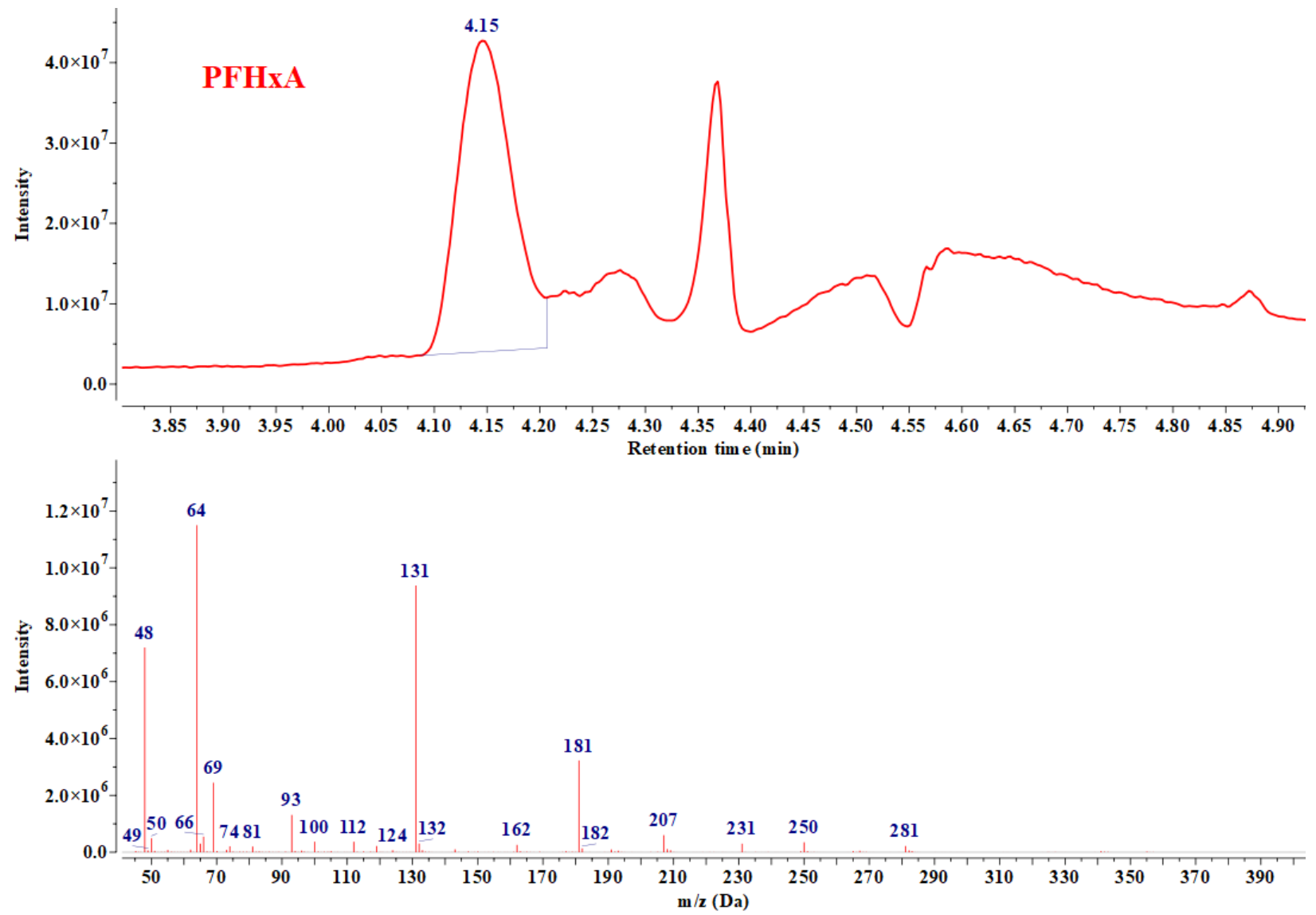

576 Figure S28. Mass spectrum and retention time for PFHxA standard injected into GC-MS 

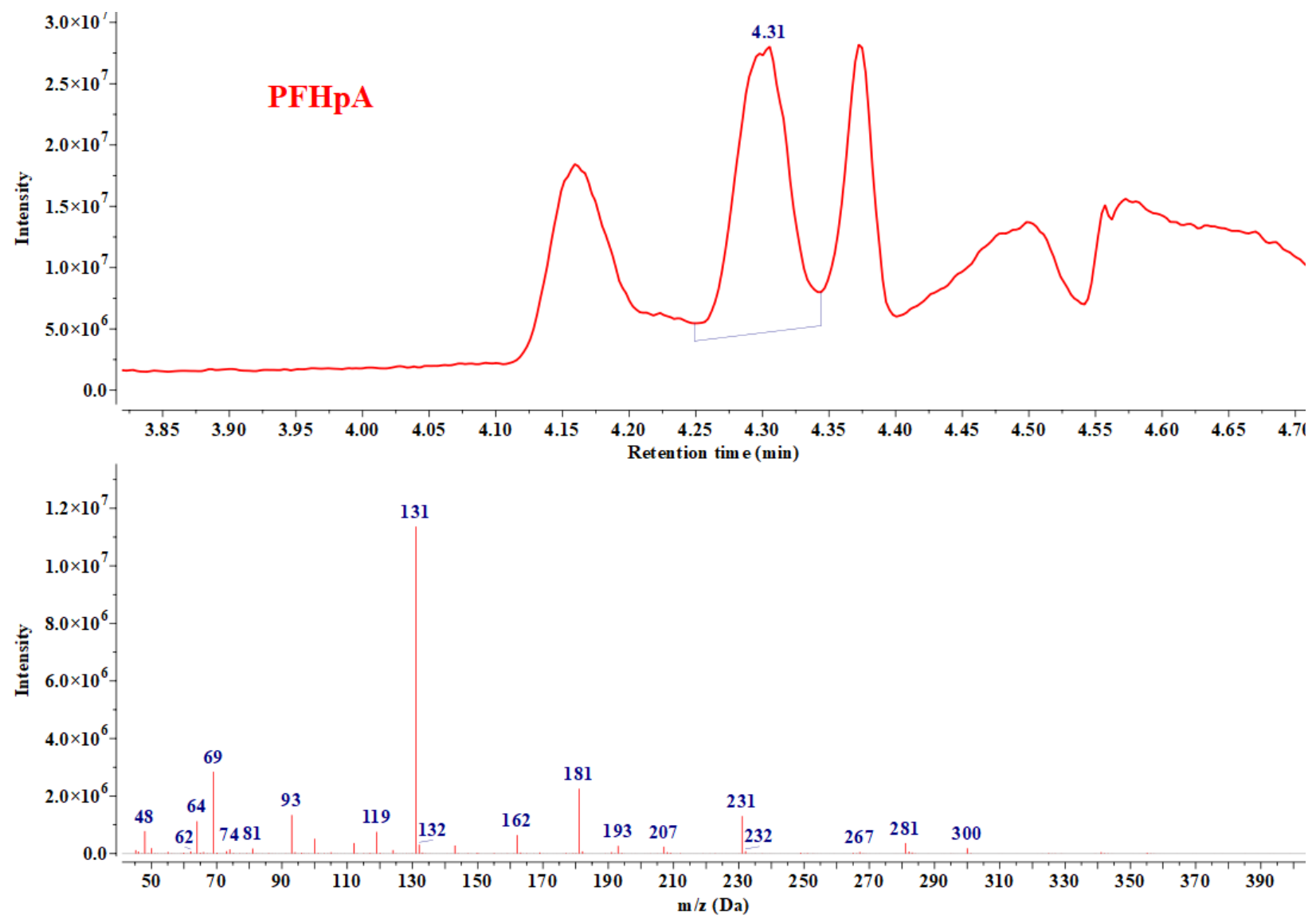

589 Figure S29. Mass spectrum and retention time for PFHpA standard injected into GC-MS 
601

602
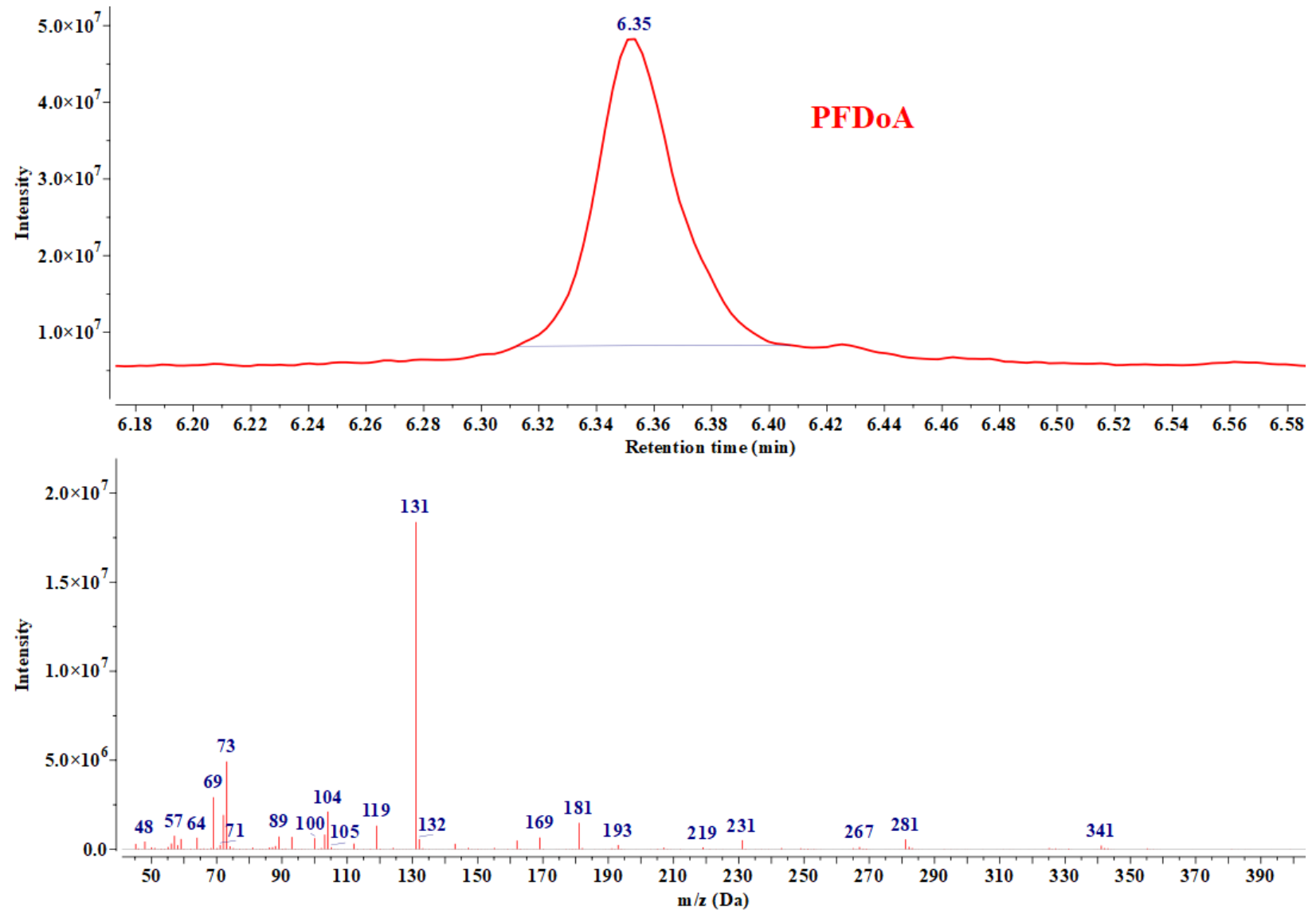

603 Figure S30. Mass spectrum and retention time for PFDoA standard injected into GC-MS

604

605

606

607

608

609

610

611

612

613 
616
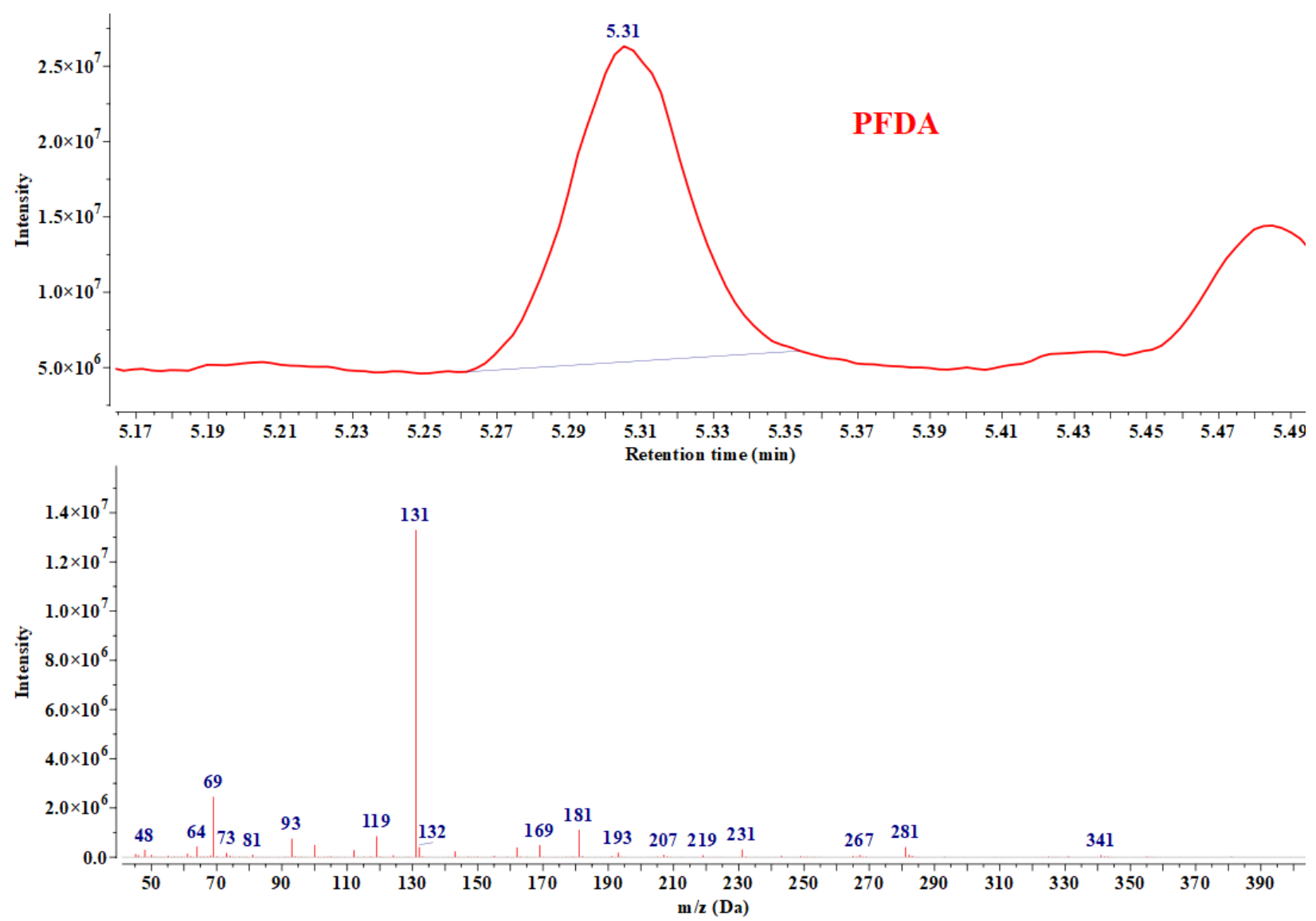

617 Figure S31. Mass spectrum and retention time for PFDA standard injected into GC-MS

618

619

620

621

622

623

624

625

626

627 

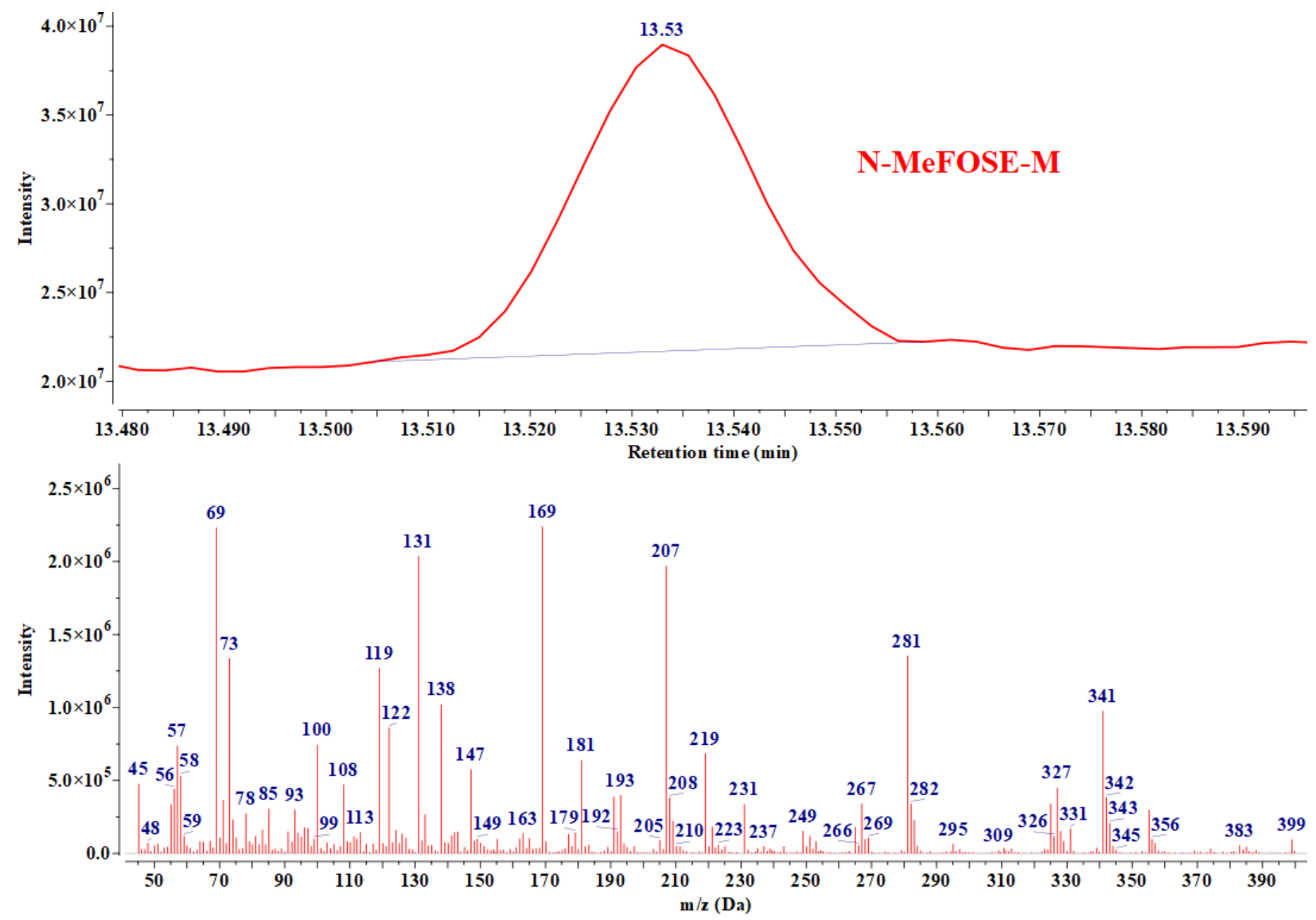

631 Figure S32. Mass spectrum and retention time for N-MeFOSE-M standard injected into GC-MS

632

633

634

635

636

637

638

639

640

641 
643

644
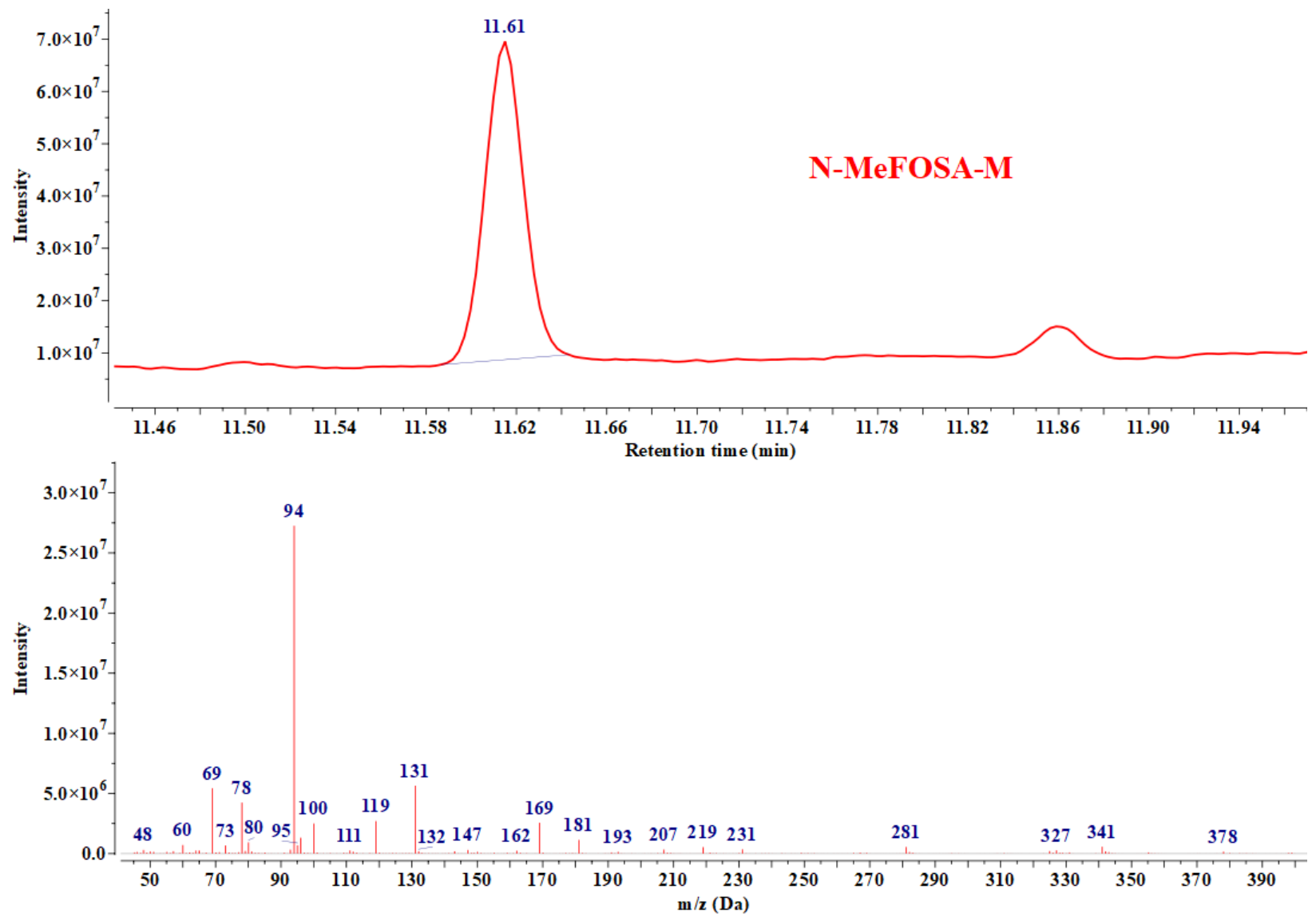

645 Figure S33. Mass spectrum and retention time for N-MeFOSA-M standard injected into GC-MS

646

647

648

649

650

651

652

653

654

655 

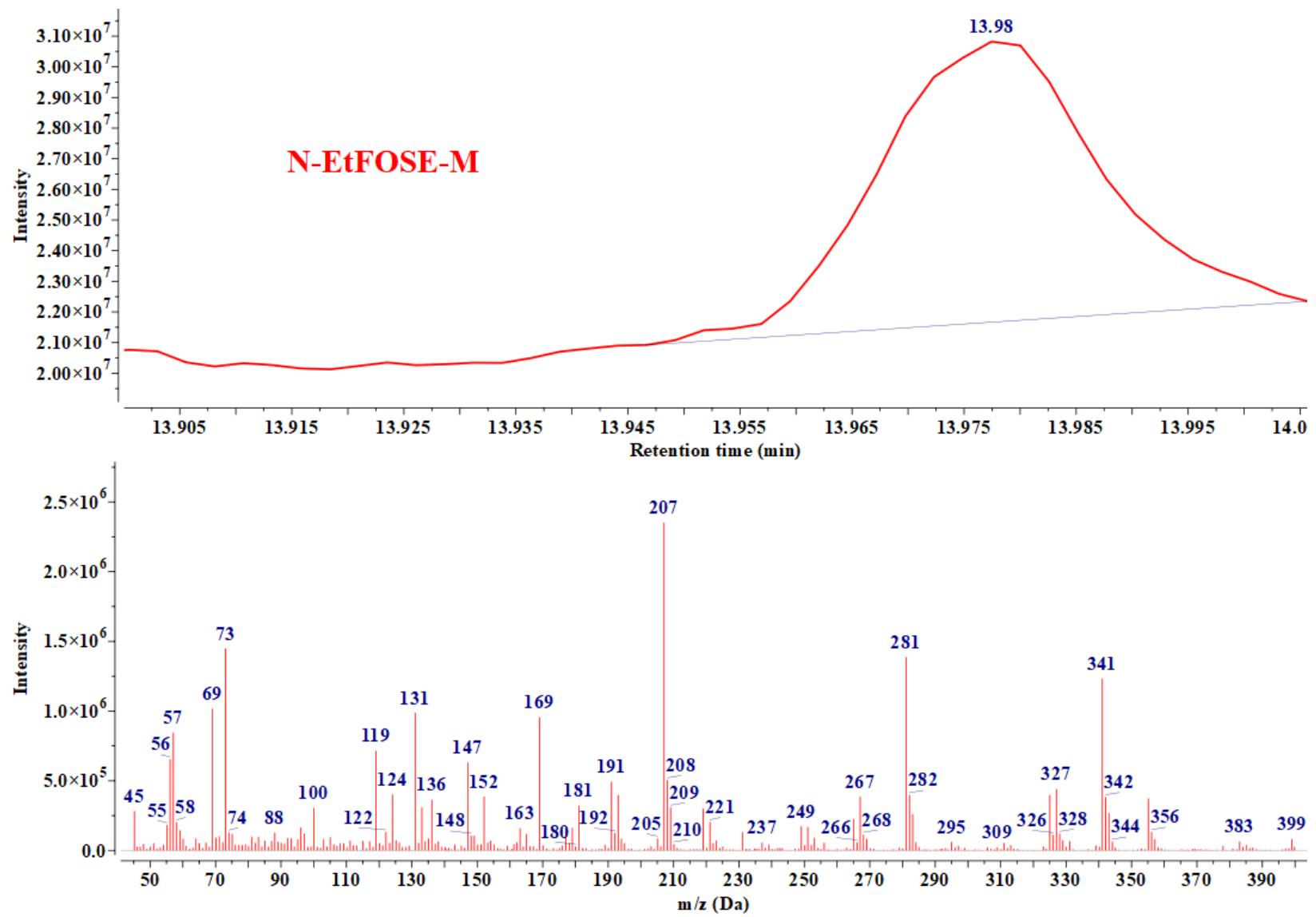

Figure S34. Mass spectrum and retention time for N-EtFOSE-M standard injected into GC-MS 
671
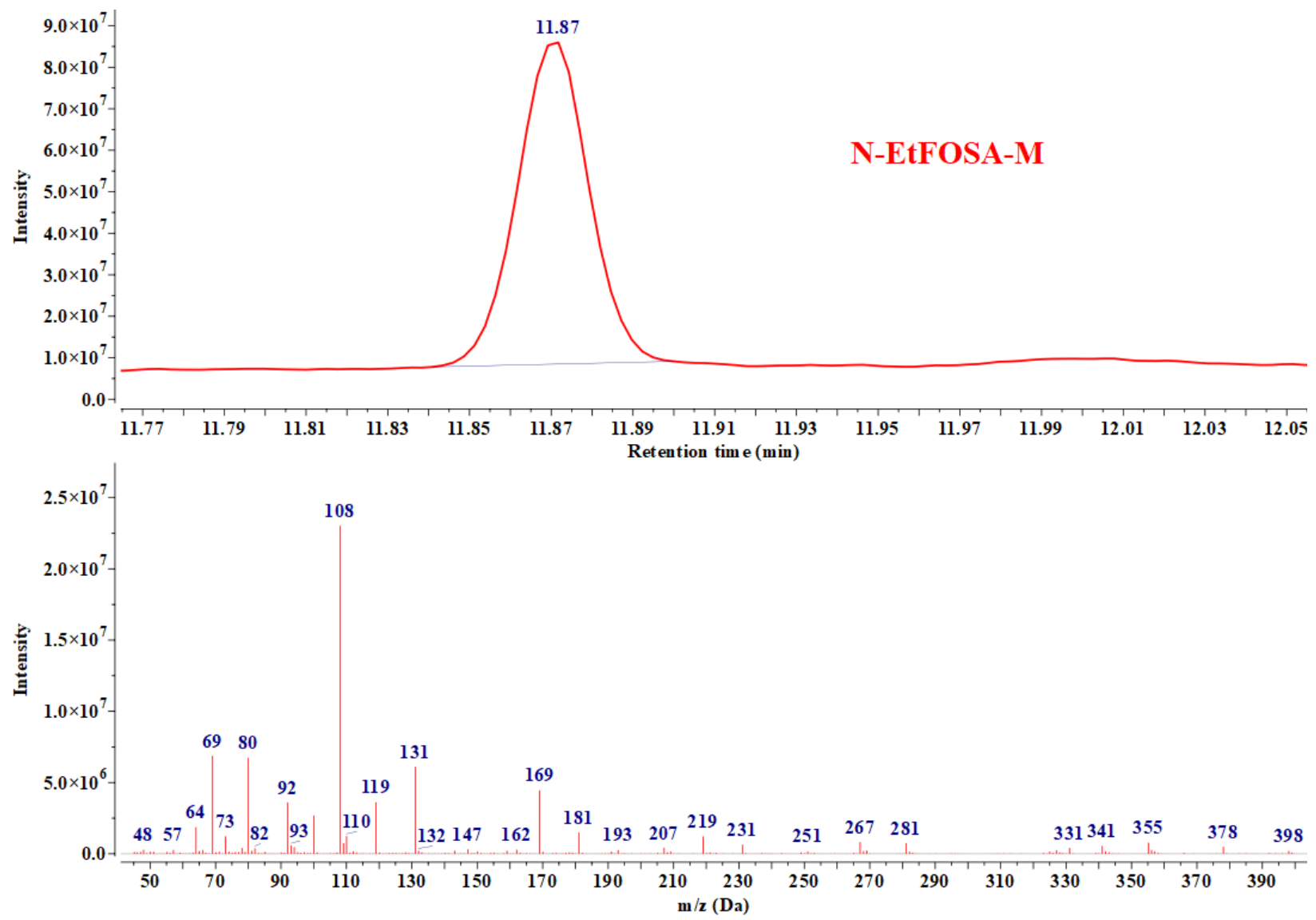

672 Figure S35. Mass spectrum and retention time for N-EtFOSA-M standard injected into GC-MS

673

674

675

676

677

678

679

680

681

682 


\section{References}

684 1. Wu, Y.; Chang, V. W., Development of analysis of volatile polyfluorinated alkyl

685 substances in indoor air using thermal desorption-gas chromatography-mass spectrometry.

686 Journal of chromatography A 2012, 1238, 114-20.

$687 \quad 2 . \quad$ Riedel, T. P.; Lang, J. R.; Strynar, M. J.; Lindstrom, A. B.; Offenberg, J. H., Gas-Phase

688 Detection of Fluorotelomer Alcohols and Other Oxygenated Per-and Polyfluoroalkyl Substances

689 by Chemical Ionization Mass Spectrometry. Environmental science \& technology letters 2019, 6,

690 (5), 289-293.

691 3. Król, S.; Zabiegała, B.; Namieśnik, J., Monitoring and analytics of semivolatile organic

692 compounds (SVOCs) in indoor air. Analytical and bioanalytical chemistry 2011, 400, (6), 1751.

6934 Guelfo, J. L.; Higgins, C. P., Subsurface transport potential of perfluoroalkyl acids at

694 aqueous film-forming foam (AFFF)-impacted sites. Environmental science \& technology 2013, 695 47, (9), 4164-4171.

696 5. USEPA, Chemistry Dashboard. https://comptox.epa.gov/dashboard. 2020.

697 6. USEPA, Technical Fact Sheet -Perfluorooctane Sulfonate (PFOS) and Perfluorooctanoic 698 Acid (PFOA). 2017.

699 7. Arp, H. P. H.; Niederer, C.; Goss, K.-U., Predicting the partitioning behavior of various

700 highly fluorinated compounds. Environmental science \& technology 2006, 40, (23), 7298-7304.

701 8. Shoeib, M.; Harner, T.; Ikonomou, M.; Kannan, K., Indoor and outdoor air

702 concentrations and phase partitioning of perfluoroalkyl sulfonamides and polybrominated

703 diphenyl ethers. Environmental science \& technology 2004, 38, (5), 1313-1320.

704 9. Krusic, P. J.; Marchione, A. A.; Davidson, F.; Kaiser, M. A.; Kao, C.-P. C.; Richardson, 705 R. E.; Botelho, M.; Waterland, R. L.; Buck, R. C., Vapor pressure and intramolecular hydrogen 
706 bonding in fluorotelomer alcohols. The journal of physical chemistry A 2005, 109, (28), 6232-

7076241.

708 10. Lei, Y. D.; Wania, F.; Mathers, D.; Mabury, S. A., Determination of vapor pressures,

709 octanol- air, and water- air partition coefficients for polyfluorinated sulfonamide,

710 sulfonamidoethanols, and telomer alcohols. Journal of chemical \& engineering data 2004, 49,

711 (4), 1013-1022.

712 11. Li, H.; Ellis, D.; Mackay, D., Measurement of low air- water partition coefficients of

713 organic acids by evaporation from a water surface. Journal of chemical \& engineering data

$7142007,52,(5), 1580-1584$.

715 12. Kutsuna, S.; Hori, H., Experimental determination of Henry's law constant of

716 perfluorooctanoic acid (PFOA) at $298 \mathrm{~K}$ by means of an inert-gas stripping method with a helical

717 plate. Atmospheric environment 2008, 42, (39), 8883-8892.

718 13. Burns, D. C.; Ellis, D. A.; Li, H.; McMurdo, C. J.; Webster, E., Experimental pKa

719 determination for perfluorooctanoic acid (PFOA) and the potential impact of pKa concentration

720 dependence on laboratory-measured partitioning phenomena and environmental modeling.

721 Environmental science \& technology 2008, 42, (24), 9283-9288.

722 14. Wallace, W. E., "Mass Spectra" in NIST Chemistry WebBook, NIST Standard Reference

723 Database Number 69, Eds. PJ Linstrom and WG Mallard, National Institute of Standards and

724 Technology, Gaithersburg MD, 20899, https://doi.org/10.18434/T4D303. In September 29, 2019.

725 15. Schymanski, E. L.; Jeon, J.; Gulde, R.; Fenner, K.; Ruff, M.; Singer, H. P.; Hollender, J.,

726 Identifying small molecules via high resolution mass spectrometry: communicating confidence.

727 Environmental science \& technology 2014, 48, (4), 2097-2098. 